\title{
Do Corporate Restructuring Announcements Imply Bad News? Evidence from Short Selling
}

\author{
Charlene Henderson \\ Nusrat Jahan \\ Kenneth Reichelt \\ Louisiana State University
}

We appreciate helpful comments from participants in the 2020 AAA Annual Meeting, the 2019 AAA Mid-Atlantic Region Meeting, and the workshop at Louisiana State University. We also acknowledge helpful comments provided by Eliza Zhang (2020 AAA Annual Meeting discussant). 


\title{
Do Corporate Restructuring Announcements Imply Bad News? Evidence from Short Selling
}

\begin{abstract}
Despite a lengthy record of research into equity market investors' short-term responses to restructuring announcements, results remain ambiguous. In this study, we investigate investors' reactions to restructuring announcements based on the behavior of short sellers. Relative to other equity investors, short sellers are better equipped to discern whether restructuring plans will succeed. In a sample of corporate restructurings announced from 2010 to 2017, we find evidence of increased trading by short sellers on and after (but not before) restructuring announcements. We find a modest but significant association between short selling activity on or after the restructuring announcement and negative future stock returns. For cost restructurings, we find evidence of a strong association between short selling activity and the restructuring announcement and negative future stock returns, but not for asset restructurings. This result suggests short sellers only trade profitably on cost restructuring announcements, meaning those firms' restructuring announcements foretold bad news.
\end{abstract}

Keywords: restructuring cost; short interest; short selling

Data Availability: All data are available from public sources mentioned in the text. 


\section{INTRODUCTION}

In this study, we examine investors' reactions to corporate restructuring announcements communicated by public corporations in U.S. Securities and Exchange Commission (SEC) filings. These filings describe management plans to change the scale of investment, reduce costs, and (or) improve efficiency (Brickley and Van Drunen 1990). Management restructures a company with the expectation that the benefits will exceed the associated costs. On this basis, investors should view any restructuring announcement as good news if they share management's assessment of future performance. However, restructuring plans are typically consequential and involve complex circumstances, making it challenging to forecast the company's future. Accordingly, some investors may disagree with management's assessment of future performance and view restructuring plans as a signal of poor future performance. For instance, Poon, Newbould, and Durtschi (2001) report evidence that "contrary to contemporary press comments, restructurings ... are typically associated with negative excess returns." On the other hand, other studies; findings suggest investors agree with managements' assessment of good news. Among others, Brickley and Van Drunen (1990) report a positive stock return from restructuring announcements that involve investment opportunities or increased efficiency.

While prior research results yield mixed evidence of reactions to restructuring announcements, these studies consistently rely on capital market returns reflecting the sentiments of a broad range of investors without distinction by the degree to which investors' are informed. Given the complexity of the setting, the restructuring announcement information is likely costly to interpret for many investors. As an alternative to a measure of broad investor reactions, we focus on the reactions of short sellers. We propose that short sellers' expertise in processing financial information equips them to better predict whether an announced corporate restructuring will lead 
to a decline in stock price. Short sellers" reputations as "skilled information processors" (Engelberg et al. 2012) lead us to rely on their trading behavior to evaluate their perception of the news in restructuring announcements. More precisely, we examine whether and how short sellers' investment decisions are associated with the information announced by restructuring companies.

To examine short sellers responses to restructuring announcements, we proceed as follows. The primary data used include the daily short data from the Financial Industry Regulatory Authority, Inc. (FINRA) (Wang et al. 2019), and restructuring announcements from SEC Form 8-K filings (2010 through 2017). ${ }^{1}$ We begin by evaluating short selling behavior in the days immediately before the announcement day, on the announcement day, and in the days immediately after announcement. ${ }^{2}$ The evidence that short selling before the announcement date does not differ from that occurring in the benchmark period rules out, in this context, short sellers' having access to information in advance of the announcement. Next, we examine activity on the day of and days following the announcement, and we find evidence of higher short selling from univariate and multivariate analysis. We then examine two types of restructuring announcements - cost restructuring and asset restructuring. ${ }^{3}$ Cost restructuring involves temporary changes to the firm's cost structure from staff layoffs and related costs that signals the firm's continued participation in a product line or business unit. On the other hand, asset restructuring is more permanent by the closure of stores and plants that sends a stronger signal that the firm is permanently scaling back their operations. We find that short sellers distinguish between these two types of announcements and that short selling interest is higher for cost

\footnotetext{
${ }^{1}$ To ensure better survivorship of our sample companies, we focus on internal corporate restructuring, rather than external corporate restructuring that include mergers and acquisitions.

${ }^{2}$ As described fully later in the paper (Section III), we use a benchmark period for each restructuring announcement. ${ }^{3}$ As described more fully in Section III, the restructuring transactions are classified as cost restructurings or asset restructurings. Briefly, asset restructurings typically involve decisions to relocate or dispose of facilities or business lines. Cost restructurings involve plans to reduce costs (including by workforce reduction) and improve efficiency.
} 
restructuring announcements. When we turn to a finer measure, exposure to restructuring costs (projected restructuring costs disclosed in the SEC filing announcing the restructuring), we again find evidence of abnormally high short selling for only the cost restructuring announcements. This result suggests that for cost restructuring firms, short sellers disagree with managements' assessments of future performance. These results are robust to several research design choices and sensitivity tests.

Finally, we examine whether the short selling activity on or after the restructuring announcement predicts a future negative stock return, and infer a profitable trade for the short sellers. ${ }^{4}$ We find modest negative stock returns for the full sample. However, when we partition the sample between cost restructuring and asset restructuring announcements, we find a significant association between short selling activity for cost restructuring announcements and negative future stock returns and no significant association with that of asset restructuring announcements. This result corroborates with findings for the short selling activity tests and suggests that short sellers profitably trade on cost restructuring announcements.

Our study contributes in the following ways. First, this study's findings contribute to understanding whether restructuring is good news or bad news to market participants (Denis and Kruse 2000; Jaggi et al. 2009). We find that short sellers' trading suggests they view restructuring announcements as bad news, particularly for cost restructurings. Second, our findings contribute to the dispute over whether short sellers trade on private or public information (Karpoff and Lou 2010; Engelberg et al. 2012; Boehmer et al. 2020). We do not find evidence that short sellers trade on private information. Instead, we find evidence that short sellers trade on public information.

\footnotetext{
${ }^{4}$ Drake et al. 2011; Engelberg et al. 2012; Christensen et al. 2014; Drake et al. 2015; Rapach et al. 2016; Kelley and Tetlock 2016.
} 
Third, our study extends research on the informativeness of SEC Form 8-K filings (Lerman and Livnat 2010; Engelberg et al. 2012; Bao et al. 2019; McMullin et al. 2019). We find that these filings are useful for informing short sellers of the nature of news in restructuring announcements. Finally, using more powerful daily short sale data instead of monthly data (Henry and Koski 2010; Christensen et al. 2014), extends the finding in Boehmer et al. (2010). The abnormal short interest and subsequent returns from cost restructuring announcements aligns with Boehmer et al.'s (2010) conclusion that short sellers succeed in identifying overvalued stocks to profitably trade, and our evidence for abnormal short interest and subsequent stock returns from asset restructurings is consistent with their conclusion that short sellers succeed in detecting undervalued stocks to avoid.

The remainder of this study is organized as follows. The next section briefly describes the restructuring context and the nature of trading by short sellers, reviews related prior research, and develops and presents hypotheses. The third section describes the sample and research methods. The next section discusses the results. The final section concludes. 


\section{THEORY AND HYPOTHESES DEVELOPMENT}

\section{Corporate Restructuring}

The Financial Accounting Standards Board (FASB) ASC 420 (formerly Statement of FAS 146 (FASB, 2002)) defines a restructuring as:

"A program that is planned and controlled by management, and materially changes either the scope of a business undertaken by an entity or the manner in which that business is conducted, as defined by the International Accounting Standard No. 37 in 2002."

International Accounting Standard 37 (IAS 37), para. 70 (IASB, 1998), goes further, noting that restructurings include the sale or termination of a line of business, moving or closing business locations, changes in management structure, and programs that have a material effect on the nature and focus of the entity's operations. This characterization fits with what Bowman and Singh (1993) describe as "organizational restructuring," the aim of which is to increase shareholder wealth by enhancing the efficiency and effectiveness of management. Studies of the pre-FAS 146 era focus on examining market reactions surrounding the restructuring action (Brickley and Van Drunen 1990), comparison of stock market return in U.S to Japan (Lee 1997), restructuring charge effects on financial analysts' forecast revisions (Chaney et al. 1999), and managers' use of the restructuring charges in earnings management (Bens and Johnson 2009; Moehrle 2002). A later stream of literature (Lee 2014; Adut et al. 2016) provides evidence of FAS 146 (June 2002) effects on financial reporting. Lee (2014) shows that the association between abnormal restructuring costs and earnings smoothing is weaker, consistent with the aim of FAS 146 to reduce the use of restructuring charges as an earnings management tool. Adut et al. (2016) includes evidence that corporations reporting restructuring charges are more likely to be the subject of a takeover in the 
market for corporate control. For restructuring charges, they report evidence of increased usefulness after FAS 146, adding to the finding in Lee (2014).

The activities undertaken in a restructuring may include cost controls, downsizing (layoffs), and asset disposals or acquisitions. Bowman and Singh (1993) describe the process as "a complex and multidimensional phenomenon." ${ }^{5}$ Notably, they indicate that restructurings involving cost savings are a more controversial source of gain to the company than sales of noncore assets. Cost restructurings entail cost-cutting efforts, including employee layoffs. Asset restructuring involves divestment of lines of businesses not fitting the core business, sales of assets or divisions, spin-offs, discontinuing operations, plant closures, relocating divisions, and facilities consolidation (Denis and Kruse 2000; Sudarsanam and Lai 2001). Generally, cost restructurings are less severe and less permanent relative to asset restructuring, because staff could be rehired in the future, while asset restructuring prevents the rehiring of staff because the plants and stores have already have been sold or closed. In this sense, investors may view cost restructuring as an inadequate response from management, and they may be skeptical that the costs incurred will exceed the expected benefits.

Results from studies examining market reactions to restructuring actions are mixed. Brickley and Van Drunen (1990) find a positive market reaction around restructuring announcements that reorganize the number of divisions or subsidiaries, suggesting that the market responds positively to information about new investment opportunities and the reduction of costs. Chalos and Chen (2002) find a positive stock market reaction to layoff announcements related to

\footnotetext{
${ }^{5}$ Their definition includes mergers and acquisitions (external restructuring), which we exclude from our analysis because ASC 420 excludes external restructuring. Rather external restructuring is covered by ASC 805 - Business Combinations.
} 
exiting unprofitable and related lines of businesses. Jaggi et al. (2009), though they widen the short-term window to one year, report positive market reactions to restructurings expected to succeed. However, other studies find the opposite market reaction, suggesting that restructuring announcements reveal bad news. Bartov et al. (1998) find a negative stock market reaction to media reports for firms with asset write-downs with no apparent change in operations, and no reaction to those involving a change in operations (e.g., plant closures, asset sales, and layoffs). Elayan et al. (1998) find a stronger negative stock market reaction for announcements by firms for which unprofitable operations are stated reason for the layoffs. The same analysis showed returns not different from zero where the announcement included restructuring as the reason. Brauer and Zimmerman (2019) report a negative market reaction to layoffs, particularly in industries that are undergoing a wave of layoffs. In short, the results of these studies suggest that restructuring announcements involve complex information that requires investors to use considerable expertise to predict the outcome of the restructuring plan.

\section{Short Selling}

In practical terms, short sellers use a trading approach that reverses the timeline used by traditional investors. ${ }^{6}$ Short sellers first borrow shares and sell them straightaway, with the aim of profiting by later replacing (repaying) the borrowed shares with shares purchased at a price lower than the earlier selling price (closing the position). Thus, short sellers' trades demonstrate their confidence in future declining stock prices. Because of the nature of their investment strategies and the potential for negative impact on markets and vulnerable registrants, over time, short selling has been regulated in several ways in the U.S. Until 2007, short selling was subject to the uptick

\footnotetext{
${ }^{6}$ The conventional long-sell involves the investor buying at a lower price than the price for which they expect to later sell (SEC 2015).
} 
rule, and since 2010, has been subject to the revised uptick rule. Regulation SHO, was adopted on January 3,2005 , with the aim to develop and standardize short selling practices and to make the short sale transactions more transparent (SEC, 2015). ${ }^{7}$ Nevertheless, clear evidence indicates regulatory constraints reduce market efficiency (e.g. Choy and Zhang, 2019).

Short selling research begins with Diamond and Verrechia (1987), which develops a model of short selling. Though early empirical studies did not show evidence of a strong link between short interest and future negative returns (e.g., Figlewski 1981; Brent, Morse, and Stice 1990), later research focused on high short interest and confirmed the expected association with subsequent negative returns (Senchack and Starks 1993; Choie and Hwang 1994; Desai et al. 2002). DeChow et al. (2001) demonstrate that short sellers' trading strategies focus on investment in stocks when they have low fundamental ratios (earnings and book values relative to market) and move to close positions when fundamentals return to normal (higher) levels. This central line of research continued to develop, bringing further evidence that short interest predicts lower future returns and consistently indications short sellers are sophisticated market participants whose trading behavior makes pricing more efficient (Lee 2001; Boehmer et al. 2008; Boehmer and Wu 2013). However, there is evidence of potentially manipulative trading behavior, which could link short sellers' trading to price inefficiencies if it drives market price below fundamental value (Goldstein and Guembel 2008; Akbas et al. 2017).

Another line of research investigates short sellers' price discovery using the public information (DeChow et al. 2001; Boehmer et al. 2008; Engelberg et al. 2012; Drake et al. 2011; Boehmer et al. 2020) and private information (Christophe et al. 2010; Akbas et al. 2017; Berkman

\footnotetext{
${ }^{7}$ SHO revisions since its enactment include 'elimination of grandfather provision' in 2007, 'options market maker exceptions' in 2008, 'close-out requirements' in 2009, and 'uptick rule' in 2010.
} 
et al. 2016). With respect to financial accounting, private information's importance to short sellers is supported by evidence that the short ratio increases in advance of SEC disciplinary actions (Karpoff and Lou 2010) and asset write-downs (Liu et al. 2012). Research also supports short sellers' behavior providing information. For example, Cassell et al. (2011) reports evidence of auditors' reliance on short ratios to signal risk of financial misstatement, Keshk and Wang (2018) demonstrate that in an over-optimistic environment, high short ratio signals to other information users and influences their beliefs.

In sum, short sellers undertake considerable effort to interpret and develop expectations a firm's future performance. Their expertise in understanding a firm's future performance better equips them to distinguish whether a corporate restructuring announcement is good news or bad news. Therefore, examining the behavior of short sellers surrounding restructuring announcements provides insight into the anticipated future performance of restructuring companies. Although this approach narrows the lens of returns, we expect it to be a more powerful source of information. ${ }^{8}$

\section{Hypotheses Development:}

\section{Information used in Short Selling}

Short sellers may trade based on private information (Gerard and Nanda 1993; Christophe et al. 2004) or on their analysis of public information (Henry and Koski 2010; Engelberg et al. 2012). Recently, Boehmer et al. (2020) using data on NYSE short sales, report

\footnotetext{
${ }^{8}$ Although data is available for another category of informed traders - institutional holders, Christensen et al. (2014) note that data for short sellers is more timely and that short sales data is more direct than broader market data from which models aim to segregate the trading of more sophisticated traders. Institutional shareholder data is reported quarterly (SEC Form 13F). Inferences about investors using metrics based on trade size (e.g. Cready and Mynatt (1991)) or trade volume (e.g. Bolster et al. (1991)) are likely noisy.
} 
evidence suggesting that after controlling for public information, short sellers know more than analysts about firm fundamentals.

Our premise is that short sellers trade on publicly available announced information about

the restructuring. However, in consideration of the possibility that short sellers may have private information on which to trade in advance of the restructuring announcement, we evaluate short interest before the restructuring announcement.

H1: On average, short selling will not be high before the restructuring announcement.

\section{Restructuring, Short Selling, and Publicly Available Information}

Short sellers' interest in corporate restructuring actions is profit driven, but the sort of information about the restructuring useful to short sellers is unclear a priori. Thus, we begin by investigating whether restructuring announcements raise short sellers' interest. Then, we consider importance of the nature of restructurings to short interest.

Generally, short sellers should participate in a stock only when expected profits exceed the costs of the short sale (Christophe et al. 2004). Because the expected profits arise from lower future prices, short selling activity should be linked with lower future cumulative market returns. In restructuring, companies face important and often extensive changes in the immediate future. Though restructurings aim for greater efficiency and improved future profitability, evidence of post-restructuring performance suggests improvements are modest (Brickley and Van Drunen 1990; Atiase et al. 2004, Cready et al. 2012, and Hill et al. 2015). Thus, the setting appears to hold appeal for short sellers. This leads to our second main hypothesis.

H2Main: On average, short selling will be higher on the day of and the days immediately following the restructuring announcement. 
Though the SEC Form 8-K restructuring announcement states the reason for restructuring, Brickley and Van Drunen (1990) identify that the real motive for managers to restructure is difficult to determine. As discussed, stock market reaction varies on whether the firm's restructuring plan will be successful, requiring considerable expertise by the short seller to predict the outcome. Short sellers would have to predict whether the restructuring plan will be unsuccessful, particularly for financially unhealthy firms (Elayan et al. 1998; Dennis and Kruse 2000).

We further investigate H2Main in three ways. First, we consider whether the nature of the restructuring activity is useful information to short sellers. Prior research (e.g., Bowman and Singh 1993) suggests greater skepticism exists about announced operational efficiencies than about sales of assets. Similarly, short sellers may be more skeptical of restructuring companies' capacity to realize the announced efficiencies, and the less permanent nature of announced layoffs may cause short sellers to judge the restructuring plan as an inadequate response from management. This suggests higher short selling for announcements of cost restructuring than for asset restructuring announcements $(\mathrm{H} 2 \mathrm{~A})$. We categorize announcements as cost restructurings if the announcement notes the plan will involve employee downsizing or other cost-cutting efforts. We categorize the announcements as asset restructurings if the announcement notes the plan involves sales of assets or divisions, plant closures or reorganizations and other activities.

H2A: Short selling on and immediately after the restructuring announcement will be higher for announcements of cost restructurings compared to asset restructurings.

Next, we use information about estimated costs associated with the restructuring to develop a measure of announced information about a restructuring. We rely on the reduced sample of 
announcements for which the SEC filing includes the estimated cost amounts. We anticipate that information about the amount of estimated costs will be useful to short sellers in evaluating the magnitude and importance of the restructuring and its prospects of success. Higher restructuring costs, especially relative to assets (as this variable is later defined), suggest the restructuring must accomplish more to succeed, implying higher short selling for announcements reporting more restructuring costs. However, it is worth noting prior research (e.g., Atiase et al. 2004, Hill et al. 2014)) reports evidence of an association between higher relative restructuring costs and better post-restructuring performance. Though on its face, this weighs against short selling, even among the more costly restructurings, short sellers may use their expertise to identify those for which post-restructuring performance will not improve.

H2B: For restructuring announcements that disclose estimated restructuring cost amounts, short selling will increase with the relative magnitude of estimated restructuring costs

Finally, FAS 146 (ASC 420-10-15-4) describes other exit activities, and includes activities which do not correspond to the transactions specifically included in the scope of ASC 420 (ASC 420-10-15-3). ${ }^{9}$ Restructurings are defined to involve material changes in the scope of the business, but the framing in ASC 420 indicates "other exit activities" are unlikely to have a material impact. We use these two categories to segregate the sample into material restructuring announcements and other exit announcements. ${ }^{10}$ We predict that short sellers will use the additional information about scope and trade more actively in the material restructuring announcements (H2C).

\footnotetext{
${ }^{9}$ The next section, Data Sources and Sample, discusses the fact that both restructurings and other exit activities are disclosed in the same section of a Form 8K filing with the Securities Exchange Commission.

${ }^{10}$ We search the keywords 'restructuring', 'restructure', 'realign', 'realignment', 'redesign', 'redesigning', 'redesign', 'refocus', 'refocusing', 'reorganization', or 'reorganize', or 'resizing' to identify explicit restructuring announcement and we define other exit announcements except the explicit restructuring announcements as other exit activities.
} 
H2C: Short selling on and immediately following restructuring announcements will be

higher for announcements of material restructurings compared to announcements of other exit activities.

\section{Restructuring, Short Selling, and Future Abnormal Returns}

As discussed earlier in the paper, short sellers undertake considerable effort to interpret information and use it to develop expectations a firm's future performance. In this study's context, this information allows them to distinguish good news and bad news corporate restructuring announcements. After examining the extent of short selling activity, we next examine whether sophisticated short sellers use their knowledge of the restructuring announcement to profitably trade. A large body of literature (Drake et al. 2011; Engelberg et al. 2012; Christensen et al. 2014; Drake et al. 2015; Rapach et al. 2016; Kelley and Tetlock 2016) acknowledges that high short sale activity is a robust predictor of subsequent stock return. Our central evaluation (H3Main) examines whether the extent of short selling activity on or after the restructuring announcement is associated with the lower future stock returns.

H3Main: Abnormal short selling on and immediately after the restructuring announcement is negatively related to future abnormal market returns.

Next, we consider whether the association between the extent of short selling and future returns suggests profitability to short sellers varies by the type of restructuring. The general skepticism of the achievability of planned efficiencies mentioned previously (e.g. Bowman and Singh 1993) suggests short sellers will focus their trades on cost restructuring announcements, expecting that future abnormal returns will be more negative for restructurings of that type. This 
suggests a stronger association between the extent of short selling and negative future abnormal returns for cost restructurings over asset restructurings (H3A).

H3A: The association between abnormal short selling on and immediately after the restructuring announcement and future abnormal market return is stronger for cost restructuring than for asset restructuring.

\section{DATA SOURCES AND SAMPLE}

We collect announcements of restructurings and of other exit activities from SEC Form 8K filings, short sale data from the Financial Industry Regulatory Authority (FINRA), financial information from Compustat, and stock market data from CRSP. ${ }^{11}{ }^{12}$ Because FINRA first reported the short sale data in August 2009, that date marks the beginning of our sample period. ${ }^{13}$ The period extends through December 2017. Our restructuring sample starts from January 2010, but we take daily short sale data from August 2009 to have a benchmark period ( 90 weekdays) before the announcement date.

\section{Restructuring Announcements}

Table 1, Panel A reports the sample selection procedure for restructuring announcements. We search SEC EDGAR (using directEDGAR) to identify restructuring announcements reported in "Item 2.05: Costs Associated with Exit or Disposal Activities" in SEC Form 8-K filings by U.S.

\footnotetext{
${ }^{11}$ FINRA is a not-for-profit organization authorized by Congress to protect investors' interests.

12 The monthly short sale transaction files provide detailed trade activity of all short sale trades reported to a consolidated tape. (FINRA 2017).

${ }^{13}$ See the notice for the short sale data description: https://www.finra.org/sites/default/files/NoticeDocument/p120044.pdf
} 
public companies in the time frame from January 2010 to December $2017 .{ }^{14}$ After eliminating duplicate and multiple announcements, we find 1,827 announcements. ${ }^{15}{ }^{16} \mathrm{Next}$, we exclude observations involving companies not in Compustat, not in CRSP, with an exchange code other than 1 or 3 (NYSE and NASDAQ), with share codes other than 10 or 11 (common shares only), organized as financial institutions, or without necessary price information in CRSP.

We isolate announcements that do not disclose a restructuring action and identify them as reporting other exit activities. ${ }^{17}$ After separating other exit activities, we are left with a final sample of 854 restructuring announcements for 574 unique companies.

From the filings, we capture the restructuring announcement date, the nature of the restructuring, reasons for restructuring, estimated restructuring costs, and an indication of cost savings from restructuring actions. We classify announcements by whether they mention "disposal of long-lived assets", "closure of plant or stores", "facilities consolidation”, "relocations”, "plan of employee termination," or other reasons for restructuring activities. Based on the disclosed nature of the restructuring, we classify announcements into two categories: 1) cost restructuring and 2) asset restructuring.

\footnotetext{
${ }^{14}$ Consider one example of how companies report a restructuring announcement in Item 2.05 in the 8-K. "Item 2.05. Cost Associated with Exit or Disposal Activities: On July 17, 2014, Microsoft announced a restructuring plan to streamline and simplify its organization and align the recently acquired Nokia Devices and Services business with the company's overall strategy." Appendix II provides other examples of restructuring announcements.

${ }^{15}$ Duplicate restructuring announcements occur because when company does not report the estimated amount of restructuring cost at the time of initial Form 8-K filing, the company must file an amended filing within four days after estimating the restructuring cost.

${ }^{16}$ If a firm announces multiple restructuring announcements within a 300-day interval, we retain only the earliest/first announcement and exclude other multiple announcements. We assume announcements separated by more than 300 days relate to different restructuring actions.

${ }^{17}$ In later analysis (Table 5, panel B), we add back the other exit activities (300 announcements) to compare explicit announcements of restructurings to other exit activities.
} 
Table 1, Panel B describes the sample's distribution across industries (Fama-French 12 classification). ${ }^{18}$ The business-equipment industry dominates by showing the greatest frequency of restructuring announcements, followed by the healthcare industry and the manufacturing industry. Cost restructuring transactions make up approximately one third of the sample (34\%), meaning asset restructurings dominate in terms of frequency.

\section{Reasons for Restructuring and Cost Savings across Restructuring Types}

Table 1, Panel C presents reasons for restructuring that are mentioned by the firm in the restructuring announcements. We find $566(66 \%)$ restructuring announcements specify the reason for restructuring and the remainder (34\%) do not mention the reason. The observed reasons for restructuring are to align with existing cost structure (42\%), challenging industry conditions or competition $(10 \%)$, to focus on core operations $(7 \%)$, low profitability/underperformance $(3 \%)$, and other reasons (3\%). ${ }^{20}$ Of the total announcements, the minority (44\%) explicitly disclosed anticipated cost savings.

\section{$<$ INSERT TABLE 1 HERE $>$}

\section{Short Sale Data}

We obtain publicly available market participants' stock level aggregate short sale data from Financial Industry Regulatory Authority (FINRA) ${ }^{21}$. Wang et al. (2019) mention that using the

\footnotetext{
${ }^{18}$ We exclude the classification for Money-Finance industry (6000-6999).

${ }^{19}$ Other reasons include inventory management, reduced demand, to relocate closer to customers, to reduce research and developments, judicial reasons, to maintain working capital requirements, and to meet environmental regulation. ${ }^{20}$ In a comment letter to the Atmel Corporation, in February 26, 2013, SEC staff mention that "In future filings, please expand your MD\&A disclosure about the restructuring charges to more fully consider the guidance from the question under SAB Topic 5-P4....... This includes whether the cost savings are expected to be offset by anticipated increases in other expenses or reduced revenues. This discussion should identify the income statement line items to be impacted and, in later periods, address whether anticipated savings were achieved."

21" Publication of daily and monthly short sale reports on the FINRA Web Site: FINRA publish on its web site short sale transaction file to provide public access to certain transaction data, including transaction times, price, and number of shares for every short sale transaction in an NMS (national market systems) stock"(FINRA 2009).
} 
new short sale dataset (publicly available disclosure on short sale activities) from FINRA provides the opportunity to examine informativeness of the short sale. Several recent studies (Jain et al. 2012; Jain et al. 2013; Berkman and Eugster 2017; Rees and Twedt 2019; Reed et al. 2019) use the publicly available short sale data from FINRA. Hu (2017) mentions that following a concern raised by the U.S. Securities and Exchange Commission about market transparency, FINRA began publishing daily aggregate short volume data for each stock in the FINRA website from $2009 .^{22}$ For sample observations, we match daily stock market-related data obtained from CRSP to daily short sale volume data obtained from FINRA (by ticker and date).

To measure short selling activity, we use the daily short interest ratio $\left(S R A T I O_{i, t}\right)$, following prior studies (Dechow et al. 2001; Asquith et al. 2005; Desai et al. 2006; Boehmer et al. 2010; Drake et al. 2011; Kecskés et al. 2013; Rapach et al. 2016; Akbas et al. 2017). For a specific security, SRATIO $i, t$ is the daily number of shares sold short (short volume) from FINRA, scaled by the number of shares outstanding from CRSP, and multiplied by 100 (expressed as a percentage). We use a second measure of short selling activity, abnormal short selling $\left(A B S S_{\mathrm{i}, \mathrm{t}}\right)$, also used in prior research (Drake et al. 2015; Christophe et al. 2004). $A B S S_{i, t}$ equals the ratio of observed daily short volume to mean short volume in a benchmark period minus 1.

\section{DESCRIPTIVE STATISTICS AND EMPIRICAL RESULTS}

\section{Descriptive Statistics}

\footnotetext{
22 "Pursuant to a Securities and Exchange Commission request, FINRA has agreed to make reported short sale trade data publicly available"(FINRA 2017).
} 
Table 2 presents descriptive statistics for the sample. Variable definitions are detailed in Appendix I. Event day is the day of the restructuring announcement. Non-event days (nonannouncement days) include a period of 90 days ending 10 days before the restructuring announcement. The mean $S R A T I O_{i, t}$ is $0.191 \%$, indicating that, on average, less than $0.2 \%$ of total shares outstanding is shorted on announcement day. The average on non-announcement days at $0.144 \%$ is significantly lower $(p<0.01)$, consistent with $\mathrm{H} 1 .{ }^{23}$

As in prior literature (Blau et al. 2013), mean price volatility $\left(P V O L T_{i, t}\right)$ on announcement days (0.042) is greater than that reported in the non-announcement days $(0.037)$. On announcement day, mean turnover for companies with restructuring announcement actions is $1.278 \%$ of shares outstanding, significantly higher than the same for non-announcement days (1.014\%).

Table 2, Panel B reports descriptive statistics for characteristics reflected in variables related to short sales, to the market, and the firm. For the full sample and after the restructuring, we observe a mean 5-day short selling ratio (SRATIO $\left.{ }_{i, t, t+4}\right)$ of 0.201 , which is larger than the mean

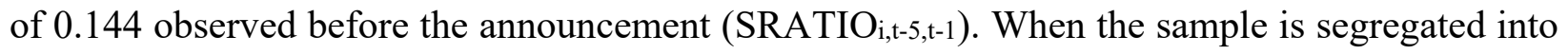
cost restructurings $(n=289)$ and asset restructurings $(n=565)$, the announcement day short ratio (SRATIO $\mathrm{i}_{\mathrm{i}, \mathrm{t}}$ is significantly larger for the cost restructuring sample $(0.221$ versus 0.176$)$. The same holds for short ratio averaged over the announcement period (SRATIO ${ }_{i, t, t+4)}$ and the mean short ratio before the announcement (SRATIO $\mathrm{i}_{\mathrm{i},-5, \mathrm{t}-1)}$ ). The planned restructuring costs of asset restructuring companies are larger than those of cost restructuring companies (RESTCOST $\left.\mathrm{T}_{\mathrm{i}, \mathrm{t}}\right)$. The characteristics of the companies' common equity securities differ significantly as well: cost restructuring companies' shares were more volatile $\left(\mathrm{PVOLT}_{\mathrm{i}, \mathrm{t}}\right)$ and turned over more quickly

\footnotetext{
${ }^{23}$ For perspective, during the sample period, the short interest across all FINRA securities averaged from a low of $.094 \%(.042 \%$ median $)$ to a high of $0.146 \%(0.065 \%$ median $)$, generally showing an increasing trend over the years 2010-2017.
} 
(TURNOVER $\mathrm{i}_{\mathrm{i}, \mathrm{t}}$. In the year before the announcement, cost restructuring companies were more over-valued (PRIORBM), smaller (PRIORSIZE), and more likely to have reported a loss (PRIORLOSS).

Table 2, Panel C presents descriptive statistics for the restructuring reasons noted in the announcements. The most frequent reason cited is to align the cost structure (42.4\%). Table 2, Panel $\mathrm{D}$ presents descriptive statistics for restructuring announcements mentioning the cost savings and not mentioning cost savings. Before and after the announcement, mean short ratio (SRATIO ${ }_{i, t}$ ${ }_{5, t-1}$ and $\left.S R A T I O_{i, t, t+4}\right)$ is significantly ( $5 \%$ level) lower for firms mentioning costs savings in the announcement compared to firms not mentioning any benefit or saving.

$<$ INSERT TABLE 2 HERE $>$

\section{Empirical Results}

Test of Hypothesis H1 and H2: Short Selling and Private Information (Public Information) about the Restructuring Plan

For H1 and H2Main, we initially evaluate the short ratio and stock returns on the days surrounding the restructuring announcement. For the full sample, Figure 1 presents the mean short ratio observed on the restructuring announcement date, 50 days before and 50 days afterward. The plotted observations show increased short selling activities on the announcement day and on days immediately afterwards. Next, we conduct a univariate event study of the short ratio on days surrounding the restructuring announcement, and an event study of the stock return surrounding the restructuring announcement. Table 3 presents the first of these results. We use a t-test to determine whether the mean $S R A T I O_{i, t}$ of stocks on and surrounding the event day differs from the 90-day benchmark period. 
In the event study analyses, Table 3 reports that daily short sale activity in the postannouncement period $(\mathrm{t}, \ldots \mathrm{t}+4)$ and averaged across the post-announcement period $\left(S R A T I O_{i, t, \mathrm{t}+4)}\right.$ is consistently higher than in the benchmark period (0.144\%), suggesting market participants short sell based on the announced (public) restructuring information. Across the pre-announcement period, mean short selling (SRATIO $\left.{ }_{i, t-5, t-1}\right)$ does not significantly differ from the benchmark period, consistent with short sellers not trading in advance of the restructuring announcement. In sum, the results reported in Table 3 suggest that short sellers trade on publicly available information (on and immediately after the release of restructuring announcement) rather than private information, and support H1.

We next consider excess returns over the same time frame before and after the restructuring announcement, against excess returns in the same benchmark period. Column 4 reports that the average excess return before the restructuring announcement $\left(R E T_{i, t-5, \mathrm{t}-1)}\right)$ is significantly higher than the benchmark period excess return $(-0.001)$. The mean excess return for the announcement date and the four days following $\left(R E T_{i, t, t+4}\right)$, is negative and significantly lower than the benchmark period. That lower return combined with the significantly higher short selling activity, suggests that short sellers may be able to profit from the subsequent price declines.

\section{$<$ INSERT TABLE 3 HERE $>$}

Finally, we consider whether the evidence in the full sample persists in the subsamples of cost and asset restructurings. Figure 2 shows that the mean short interest for both types of restructurings increase on the announcement day and days immediately after it. Consistent with the figure, Table 3, columns 2 and 3 show that short selling activity in the announcement period is significant higher $\left(S R A T I O_{i, t, t+4}\right)$ relative to the benchmark for both types of restructurings. Interestingly, Figure 3 shows a generally lower return for cost restructuring in most of the days 
following the announcement compared to that of asset restructuring, but neither type is significantly different from the return in the benchmark period (Table 3, columns 5 and 6).

\section{$<$ INSERT FIGURES 1,2,3 HERE $>$}

For the hypotheses related to short selling (H2Main, H2A), we use the following multivariate model.

$$
\begin{aligned}
\text { SRATIO }_{i, t, t+4}= & \beta_{0}+\beta_{1} \text { DUMMYREST }_{i, t}+\beta_{2} \text { RET }_{i, t, t+4}+\beta_{3} \text { RET }_{i, t-5, t-1}+\beta_{4} \text { SRATIO }_{i, t-5, t-1+}+ \\
& \beta_{5} \text { PVOLT }_{i, t, t+4}+\beta_{6} \text { PVOLT }_{i, t-5, t-1}+\beta_{7} \text { TURNOVER }_{i, t-5, t-1}+\varepsilon
\end{aligned}
$$

The model's dependent variable, $S R A T I O_{i, t, t+4}$, is the mean daily short interest ratio averaged over the days from the restructuring announcement to four days later. DUMMYREST $T_{i, t}$ is the variable of interest and equals 1 if the current day $(t)$ represents the restructuring announcement day for a company (i), and 0 for any other non-announcement day. For return measures, the variable $R E T_{i, t, t+4}$ is the contemporaneous cumulative excess return for a given company's stock, and $R E T_{i, t-5, t-1}$ is the lagged cumulative excess return. ${ }^{24}$ The model includes lagged returns to reflect short sellers' increased trading after positive returns (overreaction) and includes concurrent returns to capture their influence given the potential correlation with prior returns (Christophe et al. 2004; Diether et al. 2009).

Because short selling is autocorrelated, the model includes lagged mean short interest, $S R A T I O_{i, t-5, t-1}$ (Diether et al. 2009). To reflect the increase in short selling associated with uncertainty, we include three more control variables. First is $P V O L T_{i, t, t+4}$, mean post-

\footnotetext{
${ }^{24}$ Daily excess return $\left(R E T_{i, t}\right)$ is the difference between the raw holding period CRSP return $\left(R A W R E T_{i, t}\right)$ and the value-weighted CRSP return $\left(V R E T_{i, t}\right)$.
} 
announcement price volatility (measured as the difference between the daily high price and the daily low price, and scaled by the daily high price). Next, $P V O L T_{i, t-5, t-1}$, mean lagged price volatility is used to capture recent volatility's draw. Finally, TURNOVER, $R_{i, t, t-1-1}$ is mean lagged turnover, where turnover indicates the daily traded volume of shares scaled by shares outstanding (Diether et al. 2009, Blau et al. 2013).

Table 4 reports the correlation matrix (Spearman above, Pearson below the diagonal) for variables used in the multivariate model. From the Pearson coefficients, we note that the mean announcement period short ratio $\left(S R A T I O_{i, t, t+4}\right)$ is positively correlated with the lagged short ratio, price volatility $\left(P V O L T_{i, t, t+4}\right)$, lagged price volatility $\left(P V O L T_{i, t-5, t-1}\right)$, and lagged turnover

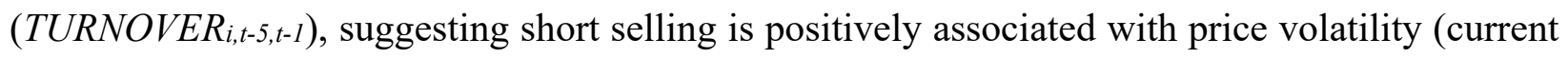
and lagged) and lagged turnover.

\section{$<$ INSERT TABLE 4 HERE $>$}

Table 5, Panel A presents the two-way fixed effects (day and stock) estimates of equation 1 for the full sample of restructuring announcements. A Hausman test rejects the presence of random effects for stocks and days. Moreover, as the standard error can be clustered along stocks and days, we report the OLS results clustering across stocks and days. In column 1, similar to Thornock (2013), we compare the announcement period with a benchmark period of nonannouncement days in the 90 days prior to announcement day (from $t-100$ to $t$-11), yielding a sample of 55,689 stock and day observations. The positive coefficient estimate for DUMMYREST ${ }_{i, t}$ $(0.028, p<0.01)$ indicates that short sale activity is significantly higher in the post-announcement period. All else equal, shares sold short relative to shares outstanding is $2.8 \%$ higher in the restructuring period. For other control variables, results are broadly similar to those in other studies (Diether et al., 2009, Blau et al. 2013). 
In column 2, for robustness as to benchmark, and we compare the announcement period with any other day in the sample period (following Blau et al. 2013), yielding a sample of $1,668,338$ stock and day observations. The coefficient estimate for DUMMYREST $T_{i, t}(0.033)$ is significant $(p<0.01)$, again indicating increased short sale activity in response to the announcement. Thus, in both benchmark formulations, H2Main is supported, demonstrating that short interest in a restructuring firm's shares increases significantly after its restructuring announcement. Control variables, including $R E T_{i, t, t+4}$ (contemporaneous return), $R E T_{i, t-5, t-1}$ (lagged return), SRATIO $O_{i, t-5, t-1}$ (lagged short sale), and TURNOVER $R_{i, t-5, t-1}$ (lagged turnover), are significantly and positively associated with the short interest ratio $\left(S R A T I O_{i, t, t+4) . P V O L T_{i, t-5, t-1} \text { is }}\right.$ significant and negatively related to the short interest ratio, consistent with Blau et al. (2013).

\section{Test of Hypothesis H2A: Short Sale, Cost Restructuring and Asset Restructuring}

For H2A, we partition the sample between the two announcement types. Table 5, Panel B, Columns 1 and 3 present the results for cost restructuring announcements. They reveal significant positive coefficient estimates for the variable DUMMYREST $T_{i, t}$, demonstrating the increased mean post-announcement short selling associated with the restructuring announcement observed for the full sample holds for the subsample of cost restructurings. Similarly, in Columns 2 and 4, the coefficient estimate for announcement date is positive and significant, again showing the observed increased short selling associated with the restructuring announcements in the full sample holds for the subsample of asset restructurings. A test of the difference in coefficient estimates on DUMMYREST $T_{i, t}$ indicates the coefficients for the two subsamples cannot be distinguished.

\section{Test of Hypothesis H2B: Short Sale and the Magnitude of Restructuring Costs}


Next, we evaluate whether short sellers use information about the magnitude of estimated restructuring costs disclosed in the SEC Form 8-K filing. We modify the sample to include only announcements which report the estimated restructuring costs in the initial Form 8-K announcement filing. This limit, combined with other missing information among control variables, reduces the sample from 854 to 702 .

We investigate the short sellers' reaction to the estimated restructuring costs using the following equation:

$$
\begin{aligned}
A B S S_{i, t, t+4}= & \beta_{0}+\beta_{1} \text { RESTRCOST }_{i, t}+\beta_{2} \text { RET }_{i, t, t+4}+B_{3} \text { RET }_{i, t-5, t-1}+\beta_{4} \text { SRATIO }_{i, t-5, t-1+}+ \\
& \beta_{5} \text { PVOLT } T_{i, t, t+4}+\beta_{6} P V O L T_{i, t-5, t-1}+\beta_{7} \text { ABVOLL L }{ }_{i, t, t+4}+\beta_{8} \text { PRIORLOSS }+ \\
& \beta_{9} \text { PRIORBM }+\beta_{10} \text { PRIORSIZE }+ \text { INDUSTRY EFFECTS }+ \text { YEAR EFFECTS }+\varepsilon
\end{aligned}
$$

Note that in this analysis, the sample composition differs from earlier analyses. The data provides 702 measures of estimated restructuring cost. As discussed in the next paragraph, the emphasis is the extent to which larger restructuring costs are associated with increased short selling.

The model's central focus is the independent variable RESTRCOST $T_{i, t}$ which equals estimated restructuring costs reported in the restructuring announcement scaled by lagged total assets. ${ }^{25}$ Where DUMMYREST used in equation (1) signals the existence of the announcement (event), RESTRCOST signals the magnitude of the event. ${ }^{26}$ More costly restructurings (relative to assets) imply more effort and skill required to succeed in a restructuring.

\footnotetext{
${ }^{25}$ We analyze total estimated restructuring cost reported in the initial announcement reported in Form 8-K, Item 2.05. This amount is expected to consistently differ from COMPUSTAT restructuring charges from the financial statements. Form 8-K reports estimated total costs at the date the firm plans for the restructuring, and financial statements report restructuring costs incurred by the end of a quarter or annual period.

${ }^{26}$ Karpoff and Lou (2010) use a similar approach by explaining abnormal short interest using the relative severity of a range of SEC enforcement actions.
} 
The dependent variable, $A B S S_{i, t, t+4}$, reflects deviations from a short selling norm, in correspondence with model's measure of restructuring costs. Consistent with prior research (Christophe et al. 2004; Drake et al. 2015), we estimate abnormal short selling as the ratio of a stock's daily short volume scaled by short volume during the benchmark period minus 1 . Abnormal short selling $\left(A B S S_{i, t, t+4}\right)$ is the mean of abnormal short selling over the 5 day announcement period.

In this model, we add a variable to control for concurrent mean abnormal trading volume, $A B V O L_{\mathrm{i}, t+4}$, to account for evidence that short sale activity and trading volume are positively related (Christophe et al. 2004).

Table 5, Panel C reports the results of estimating equation (2). The coefficient estimate for $\operatorname{RESTRCOST}_{i, t}$ for the full sample (column [1]) is not significantly different from 0 , in contrast with the positive relationship predicted in H2B. This unexpected result contradicts the usual reasoning that (all else equal) the continuous measure, RESTRCOST, should more precisely capture the relationship suggested by evidence using a categorical variable (DUMMYREST). When we consider whether abnormal short seller interest differs by the type of restructuring (cost versus asset, columns 2 and 3, respectively), the positive coefficient estimate for $R E S T R C O S T_{i, t}(6.057)$ is significantly associated with abnormal short selling only for cost restructuring announcements. Because RESTRCOST is continuous, interpreting the magnitude or economic significance of the results is meaningful. For the cost restructurings, the implication is a shift in $A B S S_{i, \mathrm{t}, t+4}$ up to $0.803 .{ }^{27} \mathrm{~A}$ test of whether the coefficient for $R E S T R C O S T_{i, t}$ differs between the two subsamples shows the coefficient estimate for Cost Restructuring transactions is significantly different. As

${ }^{27}(6.057 *$ mean RESTRCOST 0.015) + mean ABSS 0.712=0.803. 
discussed above, it is significantly positive for Cost Restructuring transactions and not significantly different from 0 for Asset Restructurings. Though merely conjecture, short sellers may discount the weight of restructuring costs for asset restructurings to the extent that the company will realize sales proceeds on the disposal of assets related to closed lines of business or facilities.

\section{Test of Hypothesis H2C: Short Selling and Restructuring vs. Other Exit Activities}

Finally, we examine whether short sale activity differs between explicit restructuring announcements and other exit activities. Panel D of Table 5 reports the estimation of equation (1) separately for explicit restructuring announcements and for other exit activities. The coefficient estimate for DUMMYREST $T_{i, t}$ is positive and significant (0.028), but only for explicit restructurings, not for other exit activities (0.014). This result supports $\mathrm{H} 2 \mathrm{C}$. The positive association between short interest and the announcement date holds only for material restructurings. It is consistent with short sellers using the information about the extent of the restructuring to target their trading.

\section{Further analysis}

To better understand differences in short selling behavior between cost restructurings and asset restructurings, we assess short selling behavior across three levels of short interest: low, medium and high. Panel E of Table 5 shows the tercile ranking of short interest on announcement day across various groups. Among cost and asset restructurings, the distribution reveals the highest number of restructurings $(40.14 \%)$ in the high short interest tercile for cost restructurings. For asset restructurings that the highest number of restructurings $(35.40 \%)$ appears in the low tercile short interest ranking. A Chi Squared test supports the significance of the different distributions of cost and asset restructurings $\left(\chi^{2}=9.167\right.$, significant at 0.010$)$. 
The second comparison contrasts explicit restructuring announcements (material in scope) to other exit activities. More restructurings materially changing the scope of business (35.25\%) appear in the high short interest tercile while the exit activities dominate in the low tercile (41.33\%). A Chi Squared test of cost restructuring versus asset restructuring groups supports the significance of the difference between the two distributions $\left(\chi^{2}=12.827\right.$, significant at 0.002$)$.

The third and fourth comparison groups focus on whether the announcement discloses reasons or not, and whether the disclosure shares the cost savings information. Among three groups of short sellers, we do not find significant differences for reasons disclosure (not disclosure) and cost savings disclosure (not disclosure).

\section{Sensitivity Tests}

To address a potential source of sample selection bias, first, Panel F (Table 5) reports the short interest surrounding the restructuring announcement in a sample reduced to exclude earnings releases (column 1) and to exclude any other Form 8-K content (column 2). We note the positive and significant coefficient estimate on DUMMYREST $T_{i, t}$ persists after excluding other publicly disclosed potentially confounding events reported in Form 8-K (columns 1 and 2). We also consider whether short selling differs by whether the restructuring announcement is the first by the firm (column 3) or one of multiple of announcements (column 4) of this nature by the firm. Again, the coefficient estimate for DUMMYREST is positive and significant in the reduced sample.

Table 5 Panel G examines whether the short seller response to restructuring announcements varies by whether the announcement disclosed (did not disclose) the reasons for the restructuring plan or the anticipated savings. In both subsamples - (columns 1 and 2$)-$ the mean announcement period short interest is positive and significant at the restructuring announcement whether or not 
the announcement includes reasons for the restructuring. Similarly, mean short interest is positive and significant at the announcement whether or not it includes disclosure of expected savings under the plan (columns 3 and 4).

$<$ INSERT TABLE 5 HERE $>$

\section{Test of H3: Short Sale and Return Predictability and Type of Restructuring:}

The third hypothesis (H3Main) assumes that short sellers use information in the restructuring announcement to predict the future abnormal market return, and to guide the extent of short trades they undertake. In other words, consistent with the short seller motive to close a position at a price lower than the initial sale, we expect higher abnormal short volume on and after the restructuring announcement will be negatively associated with future abnormal stock market return. To test our third hypothesis, we use the following multivariate regression:

$$
\begin{aligned}
\text { CAR }_{i, t+5, t+k}= & \beta_{0}+\beta_{1} \text { ABSS }_{i, t, t+4}+\beta_{2} \text { CAR }_{i, t, t+4}+\beta_{3} \text { CAR }_{i, t-5, t-1}+\beta_{4} \text { SRATIO }_{i, t-5, t-1+}+ \\
& \beta_{5} \text { PVOLT }_{i, t, t+4}+\beta_{6} \text { PVOLT }_{i, t-5, t-1}+\beta_{7} \text { ABVOL } \\
& \beta_{9, t, t+4}+\beta_{8} \text { PRIORIORL }+\beta_{10} \text { PRIORSIZE }+\varepsilon
\end{aligned}
$$

The dependent variable, $C A R_{i, t+5, t+k}$, represents the future cumulative abnormal return, and $t+k$ represents alternative future horizons. We measure future abnormal returns over several windows: 10-days, 1-month, 2-months, and 3-months. ${ }^{28}$

Abnormal short selling $\left(A B S S_{i, t, t+4}\right)$ is measured as before but in model (3) its denominator, mean benchmark period short ratio, controls for short trading for reasons unrelated to restructuring news, such as liquidity and hedging (Drake et al. 2015). We control for the average abnormal trading volume, using the five-day average of abnormal short-volume $\left(A B V O L_{i, t, t+4}\right)$ as prior

\footnotetext{
${ }^{28}$ Boehmer et al. (2008) use aggregate NYSE data to estimate the average short position in 2004 lasted 37 trading days.
} 
research mentions that short volume is positively associated with trading volume (Christophe et al. 2004; Drake et al. 2015). As in Drake et al. (2015), we estimate abnormal trading volume, using the ratio of observed trading volume to benchmark period trading volume minus 1 .

Other independent variables are included. $C A R_{i, t, t+4}$ equals the cumulative market-adjusted abnormal return on stock $i$ during the announcement period, and $C A R_{i, t-5, t-1}$, is the lagged cumulative market-adjusted abnormal return on stock $i . P V O L T_{i, t, t+4}$, reflects announcement period price volatility, while, $P V O L T_{i, t-5, t-1}$, is lagged price volatility. We control for other return relevant characteristics including PRIORLOSS (equal to 1 if in the year before the announcement a company reports negative operating income before depreciation), PRIORBM (lagged book to market ratio for common equity), and PRIORSIZE (lagged log of the market value of equity). ${ }^{29}$

The sample used in this part of the study is reduced to 753 observations because of the additional information requirements.

Table 6, Panel A columns 1 and 2 report the results of estimating equation (3) for the full sample. The central variable of interest, $A B S S_{i, t, t+4}$, has a modestly significant and negative coefficient estimate $(-0.006, \mathrm{p}<.10$ in both columns 1 and 2$)$, suggesting that abnormally high short sale activity on and immediately after the restructuring announcement is predictive of lower future abnormal market returns. These results support H3Main, but do not exhibit the desired strength of findings.

We then evaluate the association between abnormal short selling and future returns by type of restructuring: cost restructurings and asset restructurings. Analysis of the cost restructuring

\footnotetext{
${ }^{29}$ For company loss, book-to-market, and size, we use values as of the end of the year before the year in which the restructuring is announced to control for the latest publicly available financial information before the restructuring announcement date.
} 
sample shows a strong negative association (coefficient estimates -0.021 and -0.022 ), $\mathrm{p}<.01$, Columns 3 and 4) between higher abnormal short selling with lower future abnormal returns. The implied change in $\mathrm{CAR} i,+5,++14$ is notable: a decrease from 0.004 to $-0.011 .^{30}$ This relationship is not supported for asset restructurings: higher abnormal short selling is not significantly associated (coefficient estimate $-0.002, \mathrm{p}>.10$ in Columns 5 and 6 ) with future abnormal market returns.

Table 6, Panel B repeats this analysis using three alternate time periods: 1-month, 2-month, and 3-month future abnormal returns. Results are largely consistent with those in Panel A across all three alternate future time periods: the full sample shows a modestly significant and negative relationship between abnormal short selling and abnormal future returns; the cost restructuring sample shows a stronger negative association between higher abnormal short sales and future abnormal returns; and, there is no evidence supporting an association in the asset restructuring category. In short, these results support H3A.

The pattern of these findings is suggestive of the findings of Boehmer et al. (2010) who, in summarizing, note that "short sellers appear to be somewhat successful in identifying overvalued stocks to short, but they seem to be at least as adept at identifying (and avoiding) undervalued stocks" (p. 97). In this study, we report evidence of greater short interest in companies involved in cost restructurings, from announcement date (Table 5, Panels $\mathrm{C}$ and $\mathrm{E}$ ) to an association between abnormally higher short seller interest and lower future abnormal returns (Table 6 Panel A). In contrast, our study's evidence for companies undergoing asset restructurings indicates short sellers exhibit lower interest in the days before, during and after the announcement. Companies undergoing asset restructurings also report, on average, higher PRIORBM (Table 2, Panel B),

${ }^{30}$ (coefficient at mean: $-0.021 * 0.712=-0.015$; change in dependent variable $=0.004-0.015=-0.011$ ) 
which is consistent with undervaluation of market value, making them, all else equal, less appealing to short sellers. Finally, the absence of a significant association between abnormal short selling and future abnormal returns for asset restructurings is consistent with the lack of short seller interest in seeking to profit from presumed future negative returns among companies undergoing asset restructuring.

Test of H3B: Short Sale, Return Predictability, and Explicit Restructuring versus. Other Exit Activities:

Next, we test the profitability of short sellers for explicit restructuring announcements and for other exit activities. Recall that other exit activities are not part of our main sample, so we prepare a separate sample of other exit activities. Table 6, Panel $\mathrm{C}$ reports that the coefficient estimate for $A B S S_{i, t, t+4}$ is not significantly different from zero. Recall that Table 6, Panel A, major column 1 reports explicit restructuring announcements, and there, higher abnormal short selling is associated with lower future abnormal returns. The result is consistent with our prediction that short sellers are profitable (predict future abnormal market return) for explicit restructuring (material in scope) and not for the other exit activities (not material in scope).

$<$ INSERT TABLE 6 HERE $>$

\section{ROBUSTNESS}

\section{Comparison of Short Interest between Treatment Sample (announced restructuring) and Control Sample}

Our first robustness test includes examining short sellers' interest for treatment firms (that announce a restructuring action) versus control firms (that do not announce any restructuring action or report any restructuring cost). We match restructuring companies to a control sample by 
industry (two-digit SIC code), year, and assets (lagged). Our final sample consists of 1011 observations (reported in Table 7), where the number of observations in the treatment sample is 515 and the number of observations in the control sample is 496.

Table 7 reports the multivariate regression results for the following equation:

$$
\begin{aligned}
\text { SRATIO }_{i, t, t+4}= & \beta_{0}+\beta_{1} \text { RESTDUMMY }_{i, t}+\beta_{2} \text { RET }_{i, t, t+4}+\beta_{3} \text { RET }_{i, t-5, t-1}+\beta_{4} \text { PVOLT }_{i, t, t+4}+ \\
& B_{5} \text { PVOLT Ti,t-5,t-1}+B_{6} \text { TURNOVERR } \\
& \text { B }_{8} \text { PRIORLOSS }+ \text { B }_{9} \text { PRIORBM }+B_{10} \text { PRIORSIZE }+ \text { Industry Effects }+ \\
& \text { Year Effects }+\varepsilon
\end{aligned}
$$

where RESTDUMMY $Y_{i, t}$, the variable of interest, equals 1 if the company announces restructuring actions (treatment sample), and 0 otherwise (for control sample). Table 7 reports that the coefficient on RESTDUMMY $\mathrm{i}_{\mathrm{i}, t}(0.035)$ is significant and positive, after controlling for marketrelated variables and firm characteristics related variables. The results suggest that the mean short interest, measured at the time of the restructuring announcement, is higher for companies announcing a restructuring action compared to companies that do not. In short, our results are robust to a matched-pair design.

$<$ INSERT TABLE 7 HERE $>$

\section{Short Sale and Private Information:}

The results in Table 3 suggest there is no significant short selling activity in the 5 days prior to the restructuring announcement. We conduct a multivariate test where the dependent variable is mean short ratio measured over the 5 days before the announcement: $S R A T I O_{i, t-5, t-1}$. Table 8 reports that the coefficient on DUMMYREST $T_{i, t}$ is not significantly different from zero. These results are consistent with Table 3, which suggest no significant short sale activity in the 
pre-announcement period for the full sample and the subsamples (cost and asset restructurings), consistent with short sellers not trading on private information.

\section{$<$ INSERT TABLE 8 HERE $>$}

\section{State Effect, Short Sale, and Restructuring Announcements:}

The market participants' trading on restructuring actions (layoffs, plant closure, and others) may differ statewide, because US federal labor law, under the 'Worker Adjustment and Retraining Notification Act (WARN) of 1988', requires early notice of a mass layoff and plant closure. ${ }^{31}$ In addition, several states have similar acts (local WARN Act) to cover smaller layoffs, that require earlier warning of layoffs and plant closure (Chunyu and Tran 2018). Currently the states, which adopted a local WARN Act (year of adoption) are California (2003), Connecticut (1985), Hawaii (1983), Illinois (2005), Iowa(2010), Maine (1979), Minnesota (1989), New Hampshire ( 2010), New Jersey (2007), New York (2009), Tennessee (1989), Vermont (2015), and Wisconsin (1976). States that voluntarily adopted the WARN law are: Maryland (1976), Massachusetts (1984), and Michigan (1979). Interstate variations in the labor law (local Warn Act) may impact market return (Chunyu and Tran 2018). Following prior studies (Agrawal and Matsa 2013; Chunyu and Tran 2018), we match our sample of restructuring announcements for the plant closure or workforce reduction to the state where the headquarters of the firms are located. ${ }^{32}$ Table 9 reports the results of adding state fixed effects for the adoption of WARN to reduce state wide heterogeneity (column 1 through 3). In addition, Column 4 reports the short sellers' reaction to announcements for a sub-

\footnotetext{
${ }^{31}$ The Federal WARN act requires employers (with 100 or more employees) to provide 60 calendar days of advance notice for the plant closings and mass layoffs.

${ }^{32}$ Generally, employment laws or labor laws are applicable for the states where employees are working (Serfling 2016). As, according to the ASC 420, firms do not mandatorily require disclosing the state of plant closure/workforce reduction disclosure, we do not find enough observations to examine the effect of state/local WARN act. Thus, we assume that the plant closure/workforce reduction location is same as the headquarters of the firm. Following Serfling (2016), we collect the headquarter location of the firm from COMPUSTAT.
} 
sample of firms that are headquartered in any of the states having the local Warn Act (Local_Warn=1) $($ column 5 shows where Local-Warn Act $=0$ ). Our test of coefficients for the firms headquartered in the states having local Warn Act and for the firms not having headquartered in local Warn Act region show no significant difference in short sellers' reaction.

$<$ INSERT TABLE 9 HERE $>$

\section{CONCLUSION}

In this study, we examine whether short sellers trade on publicly announced information related to restructuring announcements. We provide evidence on several points. Significant short selling activity occurs on and immediately after, but not before the restructuring announcement, suggesting that in this context, short sellers trade on public information rather than private information. It also is evidence that short sellers find the information about the restructuring announced in SEC Form 8-K useful. There is higher short selling activity when estimated restructuring costs are disclosed, but for cost restructuring announcements only. Finally, we investigate the relation between abnormal short selling behavior and future abnormal stock returns. The evidence we report indicates a significant association between short sellers' abnormal interest and lower future stock returns for abnormal returns over 10 days, one month and two months. This finding holds for the full sample and for cost restructuring announcements, but not asset restructurings.

Our findings that contrast cost restructuring and asset restructuring are supported in prior studies. For instance, analyzing Fortune's America's Most Admired Companies survey, Flanagan and O'Shaughnessy (2005) report that cost restructuring has a negative impact on a firm's reputation and this relationship is significantly stronger for newer firms. On the other hand, asset 
restructuring often is used as a tool to repay debt and may not necessarily relate to improvements in firm efficiency. As noted in the discussion of Table 6 results, prior to the restructuring, asset restructuring companies appear to be undervalued, making their stock less appealing as a prospect for future price declines and as an investment for short sellers. Consequently, short sellers may profit from short selling on cost restructuring actions. As discussed above, these distinct results between restructuring types are consistent with the observation in Boehmer et al. (2010) that short sellers are able to identify which stocks to short (cost restructurings) and which stocks to avoid (asset restructurings). 


\section{APPENDIX I: Variable Description}

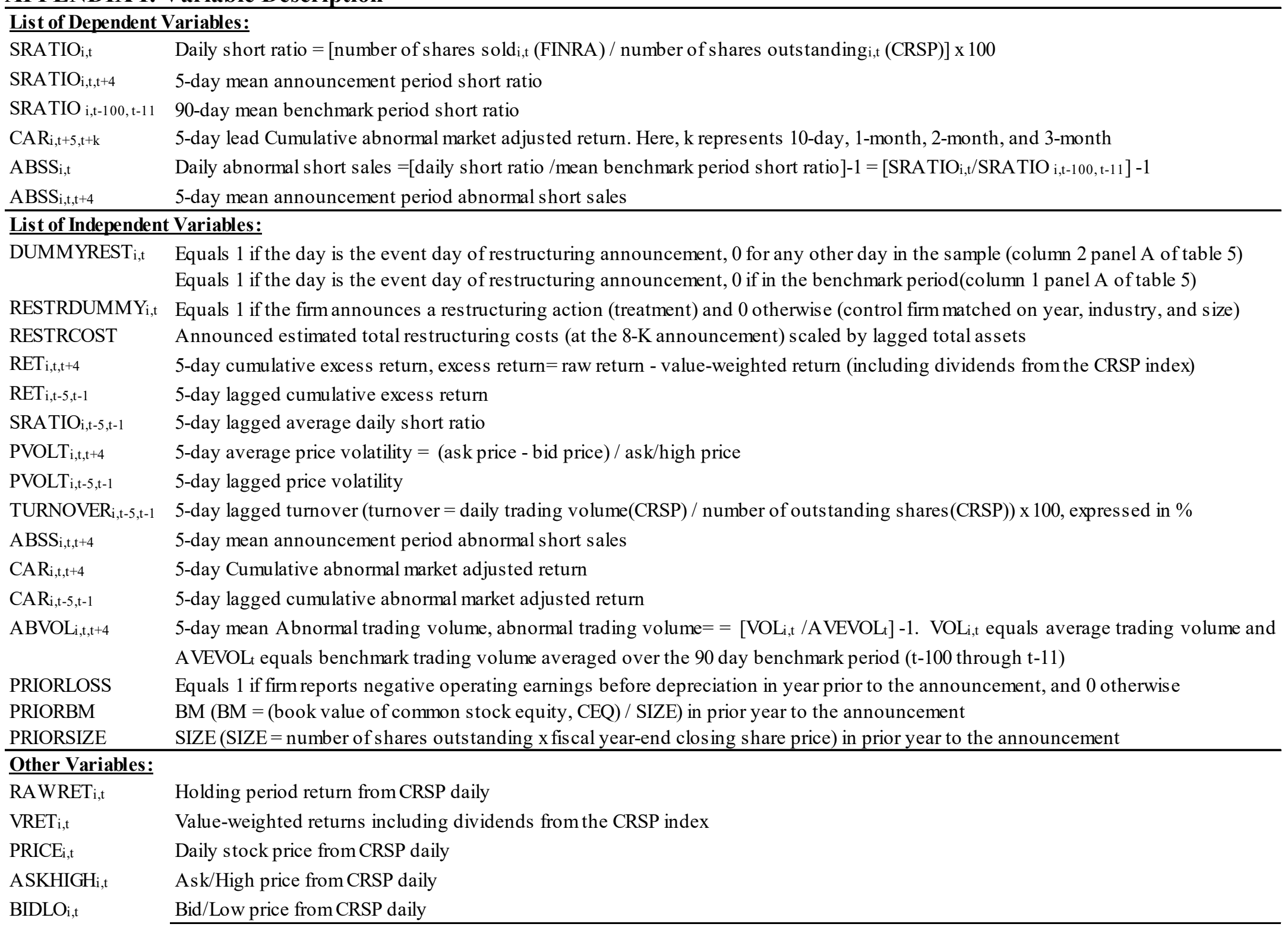




\title{
APPENDIX II: Restructuring Announcements from 8-K Filings
}

\begin{abstract}
A. Types of Restructuring Announcements:
1. Cost Restructuring:

Item 2.05 Costs Associated with Exit or Disposal Activities. On September 4, 2013, Brocade Communications Systems, Inc. (the "Company") committed to a workforce reduction plan intended to realign resources in connection with its previously announced data center and software-defined networking strategies and cost reduction initiatives. The workforce reduction plan impacts approximately 300 notified employees worldwide. The Company expects to incur aggregate charges of approximately $\$ 20$ to $\$ 25$ million for severance and other employee termination costs associated with the workforce reduction plan. All of these charges are expected to be cash expenditures. The Company's current headcount, excluding the notified employees, is approximately 4,180.
\end{abstract}

2. Asset restructuring:

2.1 Facilities consolidation: Item 2.05. Costs Associated with Exit or Disposal Activities. On October 11, 2012, Carter's, Inc. (the "Company") announced plans to consolidate its retail store and financial operations currently managed in its Shelton, Connecticut facility with the Company's Atlanta, Georgia -based operations. To enable the consolidation of these operations and to support its growth plans, the Company is evaluating its long-term space needs in the Atlanta area. The Company expects to complete this consolidation by the end of 2013.

2.2 Plant Closure: Item 2.05. Costs Associated with Exit or Disposal Activities. On June 29, 2017, Tenneco Inc. determined to undertake a restructuring initiative and close its Clean Air manufacturing plant in O'Sullivan Beach, Australia when General Motors and Toyota end vehicle production in the country, which is expected to occur in October 2017. This initiative may include additional restructuring actions with respect to the company's local original equipment Ride Performance operations. All such restructuring activities related to this initiative are expected to be completed by the first quarter of 2018.

2.3 Relocation: Item 2.05. Costs Associated with Exit or Disposal Activities. The St. Joe Company (the "Company") announced on March 17,2010 that it is relocating its corporate headquarters from Jacksonville, Florida to its large-scale development project adjacent to the new Northwest Florida Beaches International Airport in Bay County, Florida. The Company will also be consolidating existing offices from Tallahassee, Port St. Joe and South Walton County into the new location. The relocation is expected to be completed by the summer of 2011 .

B. Cost Savings Disclosure:

Item 2.05 Costs Associated with Exit or Disposal Activities: On March 4, 2016, the board of directors of Impax Laboratories, Inc. (the "Company") approved a restructuring plan (the "Plan") designed to reduce costs, improve operating efficiencies and enhance the Company's long term competitive position. The Plan involves the closure of the Company's Middlesex, New Jersey manufacturing and packaging site and a related reduction in workforce of approximately 213 positions at the site over the following 24 months. Pursuant to the Plan, products currently manufactured at the Company's Middlesex facility will be transferred to the Company's other facilities or to third party manufacturers. The Plan does not impact the Company's research and development (R\&D) activities at the Middlesex site. The Company currently expects the Plan to achieve annualized cost savings of between \$23 million to \$27 million and to realize these savings beginning in 2017.

C. WARN Act Effect:

Item 2.05 Costs Associated with Exit or Disposal Activities: On March 5, 2010, XenoPort, Inc. (the "Company") implemented a restructuring that includes an overall reduction in its workforce of approximately $50 \%$. The Company notified employees affected by the restructuring on March 5, 2010. The Company is providing affected employees with up to sixty (60) days of leave of absence pay in accordance with the Worker Adjustment and Retraining Notification Act. Affected employees may also be eligible to receive severance payments, transition pay, continuation of medical insurance under COBRA and a two-year extension of exercisability of vested stock options as of May 4, 2010. The Company expects to complete the restructuring in May 2010. 
FIGURE 1

Short Ratio Surrounding the Restructuring Announcement Date

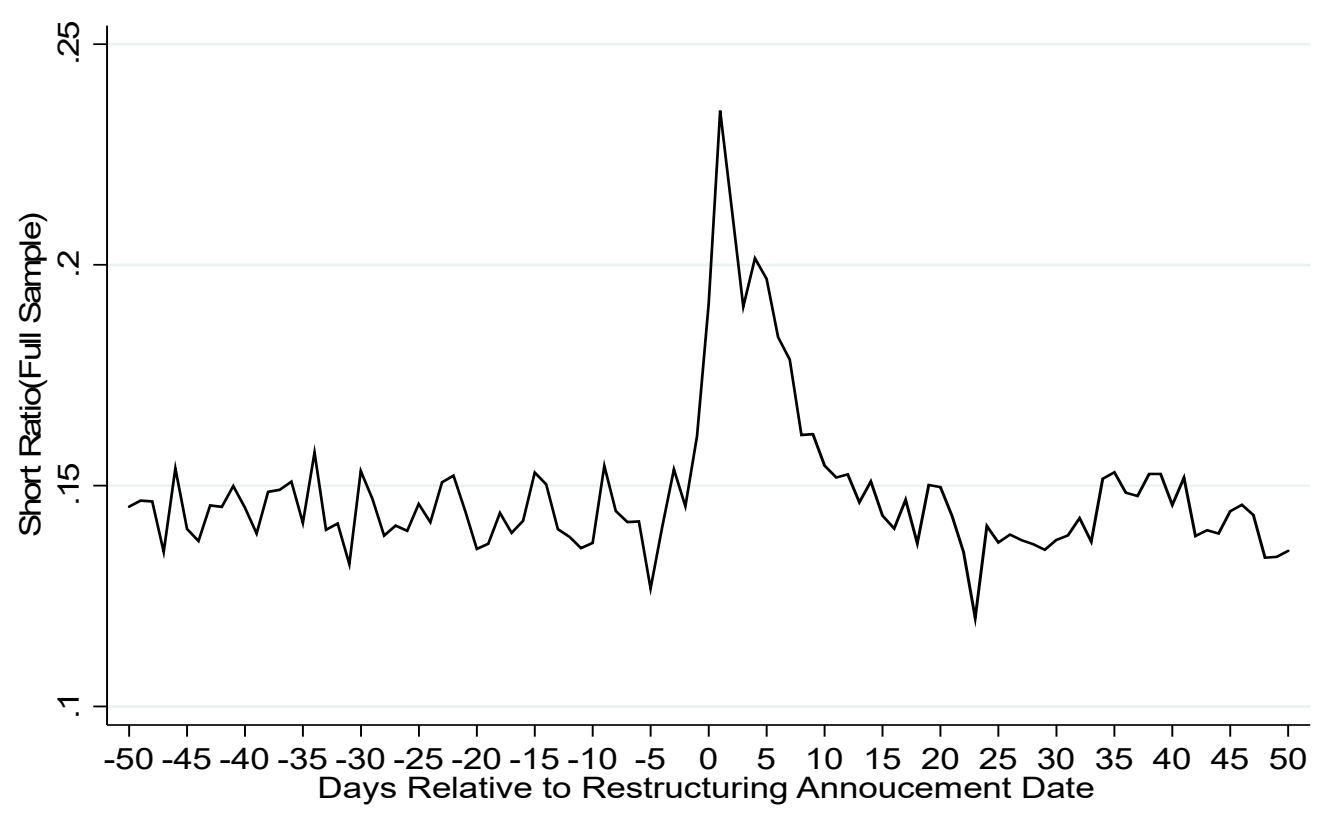

FIGURE 2

Short Ratio Surrounding Restructuring Announcement Date by Restructuring Type

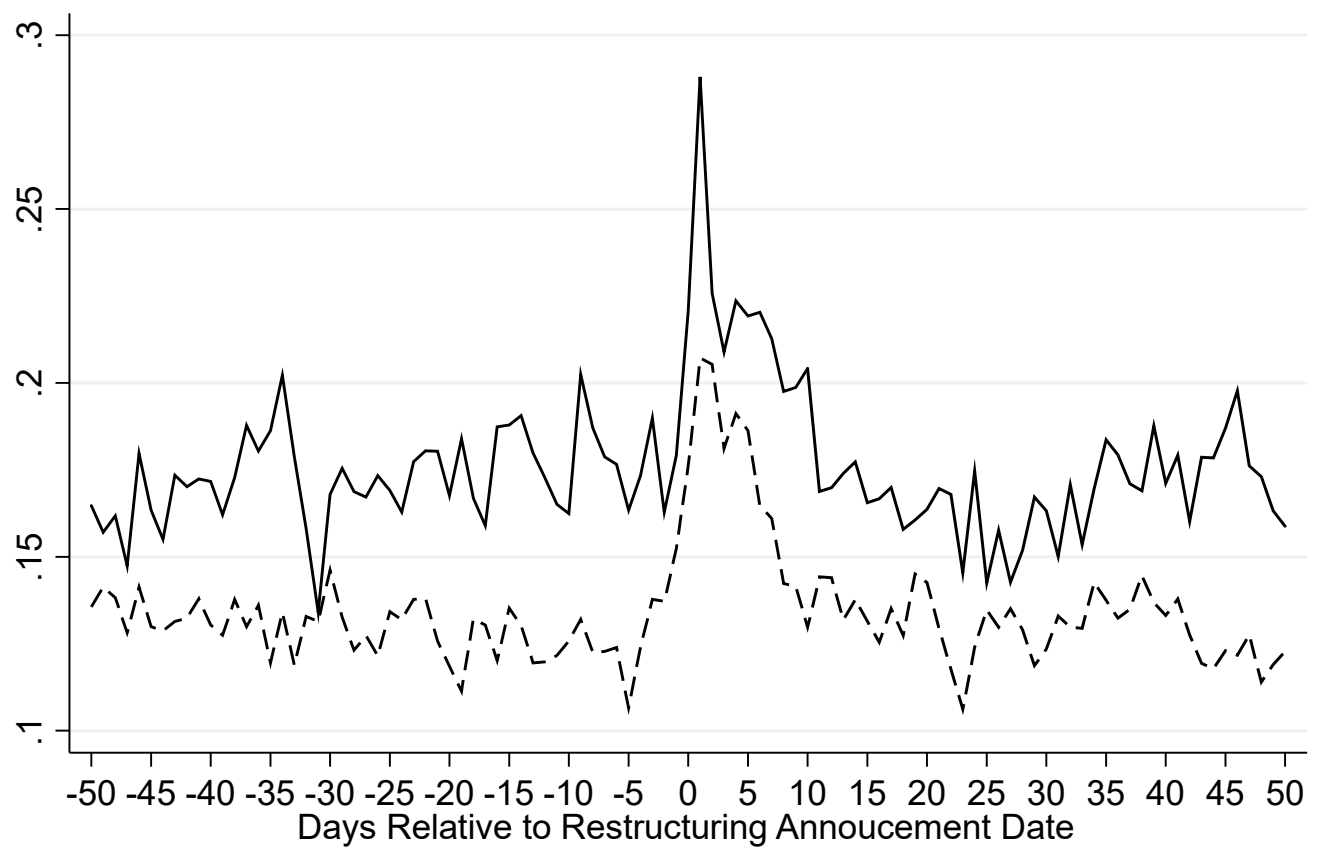


FIGURE 3

Excess Return on and after Restructuring Announcement Date by Restructuring Type

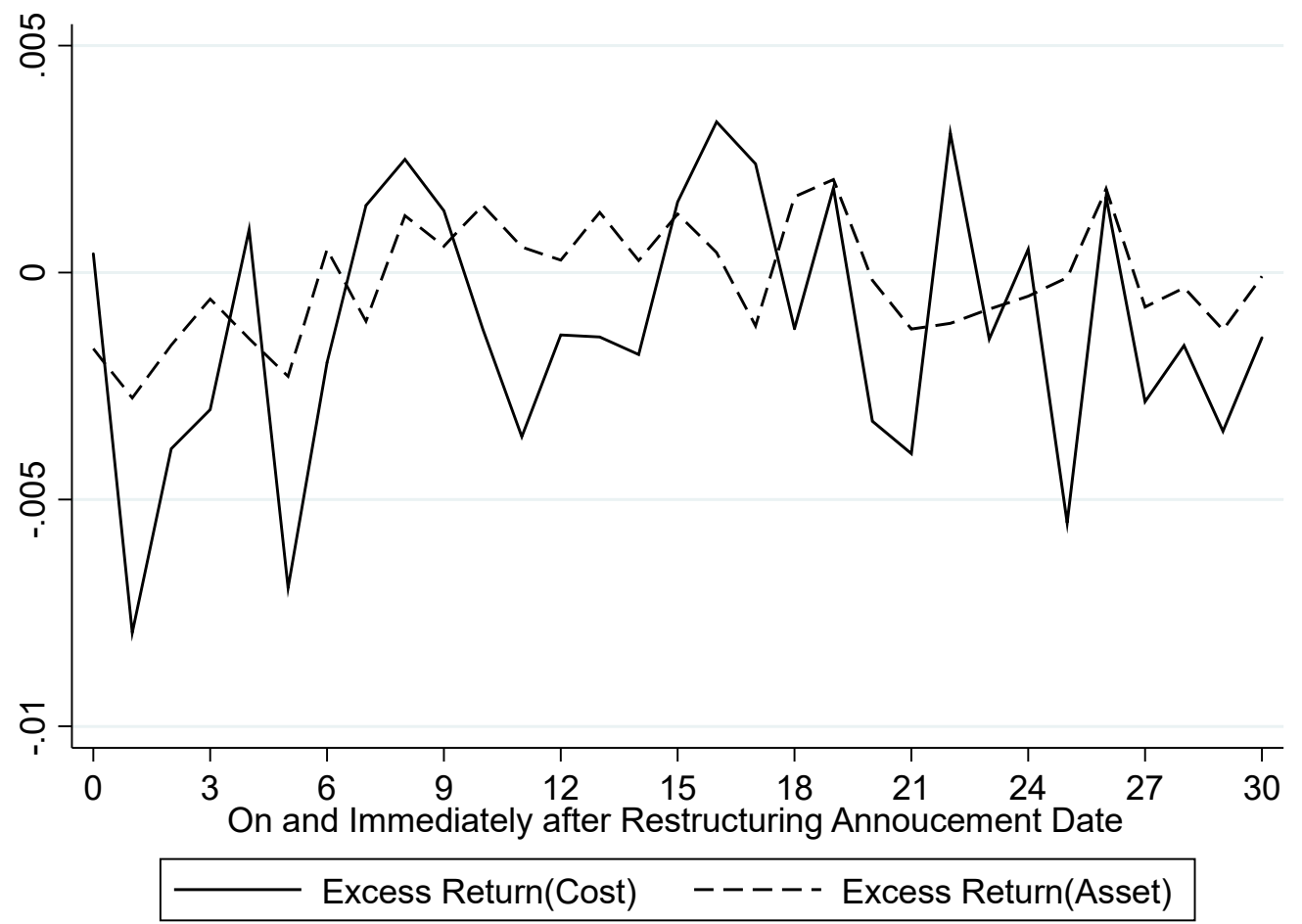

Excess return $=$ raw return - value-weighted return $\mathrm{RET}_{\mathrm{i}, \mathrm{t}, \mathrm{t}+4}=5$ day cumulative excess return $=5$ day 


\section{REFERENCES}

Adut, D., A. D. Holder, and A. Robin. 2016. Restructuring charges and takeover likelihood: Evidence from the pre-and post-SFAS 146 eras. Journal of Accounting \& Public Policy 35 (2):192-207.

Agrawal, A. K., and D. A. Matsa. 2013. Labor unemployment risk and corporate financing decisions. Journal of Financial Economics 108 (2):449-470.

Akbas, F., E. Boehmer, B. Erturk, and S. Sorescu. 2017. Short interest, returns, and unfavorable fundamental information. Financial Management 46 (2):455-486.

Asquith, P., P. A. Pathak, and J. R. Ritter. 2005. Short interest, institutional ownership, and stock returns. Journal of Financial Economics 78 (2):243-276.

Atiase, R. K., D. E. Platt, and S. Y. TSE. 2004. Operational restructuring charges and postrestructuring performance. Contemporary Accounting Research 21 (3):493-522.

Bens, D. A., and R. Johnston. 2009. Accounting discretion: Use or abuse? An analysis of restructuring charges surrounding regulator action. Contemporary Accounting Research 26 (3): 673-699.

Bao, D., Y. Kim, and G. M. Mian. 2019. Do managers disclose or withhold bad news? Evidence from short interest. The Accounting Review 94 (3): 1-26)

Bartov, E., F. W. Lindahl, and W. E. Ricks. 1998. Stock price behavior around announcements of write-offs. Review of Accounting Studies 3: 327-346.

Berkman, H., and M. Eugster. 2017. Short on drugs: Short selling during the drug development process. Journal of Financial Markets 33:102-123.

Blau, B. M., T. J. Brough, J. L. Smith, and N. M. Stephens. 2013. An examination of short selling activity surrounding auditor changes. Journal of Accounting, Auditing \& Finance 28 (4):348-368.

Boehmer, E., Z. R. Huszar, and B. D. Jordan. 2010. The good news in short interest. Journal of Financial Economics 96 (1):80-97.

Boehmer, E., C. M. Jones, J. Wu, and X. Zhang. 2020. What do short sellers know? Review of Finance forthcoming.

Bowman, E. H., and H. Singh. 1993. Corporate restructuring: Reconfiguring the firm. Strategic Management Journal 14: 5-14.

Brickley, J. A., and L. D. Van Drunen. 1990. Internal corporate restructuring : An empirical analysis. Journal of Accounting and Economics 12 (1-3):251-280. 
Chaney, P. K., C. E. Hogan, and D. C. Jeter. 1999. The effect of reporting restructuring charges on analysts' forecast revisions and errors. Journal of Accounting \& Economics 27 (3):261-284.

Choy, S. K., and H. Zhang. 2019. Public news announcements, short-sale restriction and informational efficiency. Review of Quantitative Finance and Accounting 52(1): 197-229.

Christensen, T. E., M. S. Drake, and J. R. Thornock. 2014. Optimistic reporting and pessimistic investing: Do pro forma earnings disclosures attract short sellers? Contemporary Accounting Research 31 (1):67-102.

Christophe, S. E., M. G. Ferri, and J. J. Angel. 2004. Short-selling prior to earnings announcements. The Journal of Finance 59 (4):1845-1876.

Christophe, S. E., M. Ferri, and J. Hsieh. 2010. Informed trading before analyst downgrades: Evidence from short sellers. Journal of Financial Economics 95 (1): 85-106.

Chunyu, L., and A. L. Tran. 2018. Labor Restructuring and Acquisitions: Evidence from State Adoption of the Worker Adjustment and Retraining Notification Act. Available at SSRN 3333114.

Cready, W. M., and P. Mynatt. 1991. The information content of annual reports: A price and trading response analysis. The Accounting Review 66(2): 291-312.

Cready, W. M., T. J. Lopez, and C. A. Sisneros. 2012. Negative special items and future earnings: expense transfers or real improvements? The Accounting Review 87(4): 1165 1195.

Dechow, P. M., A. P. Hutton, L. Meulbroek, and R. G. Sloan. 2001. Short sellers, fundamental analysis, and stock returns. Journal of Financial Economics 61 (1):77-106.

Dennis, D., J., and T. A. Kruse. 2000. Managerial discipline and corporate restructuring following performance declines. Journal of Financial Economics 55: 391-424.

Desai, H., K. Ramesh, S. R. Thiagarahan and B. V. Balachandran. 2002. An investigation of the information role of short interest in the nasdaq market. Journal of Finance 57 (5): 22632287.

Desai, H., S. Krishnamurthy, and K. Venkataraman. 2006. Do short sellers target firms with poor earnings quality? Evidence from earnings restatements. Review of Accounting Studies 11 (1):71-90.

Diether, K. B., K. Lee, I. M. Werner. 2009. Short-sale strategies and return predictability. The Review of Financial Studies 22 (2): 575-607.

Drake, M. S., L. A. Myers, S. Scholz, and N. Y. Sharp. 2015. Short selling around restatement announcements: When do bears pounce? Journal of Accounting, Auditing \& Finance 30 (2):218-245. 
Drake, M. S., L. Rees, and E. P. Swanson. 2011. Should investors follow the prophets or the bears? Evidence on the use of public information by analysts and short sellers. The Accounting Review 86 (1):101-130.

Engelberg, J. E., A. V. Reed, and M. C. Ringgenberg. 2012. How are shorts informed?: Short sellers, news, and information processing. Journal of Financial Economics 105 (2):260278.

Figlewski, S. 1981. The information effects of restrictions on short sales: some empirical evidence. Journal of Financial and Quantitative Analysis 16

Financial Accounting Standards Board (FASB). 2002. Statement of Financial Accounting Standards No. 146 - Accounting for Costs Associated with Exit or Disposal Activities. Norwalk, CT: FASB.

FINRA. 2009. Publication of Daily and Monthly Short Sale Reports on the FINRA Web Site.

- 2017. TRF Regulation SHO - 2017.

Gerard, B., and V. Nanda. 1993. Trading and manipulation around seasoned equity offerings. The Journal of Finance 48 (1):213-245.

Goldstein, I., and A. Guembel. 2008. Manipulation and the allocation role of prices. Review of Economic Studies 75: 133-164.

Henry, T. R., and J. L. Koski. 2010. Short selling around seasoned equity offerings. The Review of Financial Studies 23 (12):4389-4418.

Hill, M. S., P. M. Johnson, K. X. T. Liu, and T. J. Lopez. Operational restrcturings: where's the beef? Review of Quantitative Finance and Accounting 45: 721-755.

Hu, D. 2017. Does the public availability of market participants' trading data affect firm disclosure? evidence from short sellers. Evidence from Short Sellers (April 30, 2017).

Huszár, Z. R., R. S. Tan, and W. Zhang. 2017. Do short sellers exploit industry information? Journal of Empirical Finance 41:118-139.

International Accounting Standards Board (IASB). 1998. IAS 37 Provisions, Contingent Liabilities, and Contingent Assets. London: IFRS Foundation

Jaggi, B., B. Lin, S. Govindaraj, and P. Lee. 2009. The value relevance of corporate restructuring charges. Review of Quantitative Finance and Accounting 32: 101-128.

Jain, A., P. K. Jain, T. H. McInish, and M. McKenzie. 2013. Worldwide reach of short selling regulations. Journal of Financial Economics 109 (1):177-197.

Jain, C., P. Jain, and T. H. McInish. 2012. Short selling: the impact of SEC rule 201 of 2010. Financial Review 47 (1):37-64. 
Jiang, H., A. Habib, and M. M. Hasan. 2020. Short selling: A review of the literature and implications for future research. Working paper. 2020. forthcoming in European Accounting Review.

Kecskés, A., S. A. Mansi, and A. Zhang. 2013. Are short sellers informed? Evidence from the bond market. The Accounting Review 88 (2):611-639.

Keshk, W. and J. J. Wang. 2018. Determinants of the relationship between investor sentiment and analysts' private information production. Journal of Business, Finance and Accounting 45 (9-10): 1082-1099.

Lee, P. M. 1997. A comparative analysis of layoff announcements and stock price reactions in the United States and Japan. Strategic Management Journal 18 (11):879-894.

Lee, Y. G. 2014. An examination of restructuring charges surrounding the implementation of SFAS 146. Review of Accounting Studies 19 (2):539-572.

Lerman, A., and J. Linvat. 2010. The new Form 8-K disclosures. Review of Accounting Studies 15: $752-778$.

McMullin, J. L., B. P. Miller, and B. J. Twedt. 2019. Increased mandated disclosure frequency and price formation: Evidence from the 8-K expansion regulation. Review of Accounting Studies 24: 1-33.

Moehrle, S. R. 2002. Do firms use restructuring charge reversals to meet earnings targets? The Accounting Review 77 (2):397-413.

Poon, P. S., G. D. Newbould, and C. Durtschi. 2001. Market reactions to corporate restructurings. Review of Quantitative Finance and Accounting

Rapach, D. E., M. C. Ringgenberg, and G. Zhou. 2016. Short interest and aggregate stock returns. Journal of Financial Economics 121 (1):46-65.

Reed, A. V., M. Samadi, and J. S. Sokobin. 2019. Shorting in broad daylight: Short sales and venue choice. Kenan Institute of Private Enterprise Research Paper (18-14):18-27.

Rees, L. L., and B. J. Twedt. 2019. The Incremental Value Relevance of Media Coverage of Earnings Announcements: Evidence from the Trading of Short Sellers. Available at SSRN 3047383.

Serfling, M. 2016. Firing costs and capital structure decisions. The Journal of Finance 71 (5):2239-2286.

Sudarsanam, S. and J. Lai. 2001. Corporate financial distress and turnaround strategies: an empirical analysis. British Journal of Management 12: 183-199.

Thornock, J. 2013. The effects of dividend taxation on short selling and market quality. The Accounting Review 88 (5):1833-1856. 
U.S. Securties and Exchange Commission (SEC). "Investor Information - Fact Answers -Short Sales.” last modified April 12, 2015 https://www.sec.gov/answers/shortsale.htm.

Wang, X., X. S. Yan, and L. Zheng. 2019. Shorting flows, public disclosure, and market efficiency. Journal of Financial Economics. 
TABLE 1

Panel A: Sample Selection Procedure

\begin{tabular}{|c|c|c|}
\hline Sample Characte ristics & $\begin{array}{r}\text { Total } \\
\text { Observations } \\
\end{array}$ & $\begin{array}{c}\text { Unique Firm } \\
\text { Observations }\end{array}$ \\
\hline Restructuring announcements from January 2010 to December 2017 & 2,445 & 1,264 \\
\hline \multicolumn{3}{|l|}{ Excluding: } \\
\hline duplicate announcements by CIK and announcement date & $(113)$ & $(0)$ \\
\hline multiple announcements within 300-day interval & $(505)$ & $(0)$ \\
\hline observations not in COMPUSTAT & $(251)$ & $(183)$ \\
\hline observations not in CRSP & (104) & $(81)$ \\
\hline $\begin{array}{l}\text { observations with exchange code in CRSP other than } 1 \text { or } 3 \\
\text { and with share code other than } 10 \text { or } 11\end{array}$ & $(63)$ & $(42)$ \\
\hline observations with SIC codes 6000-6999 & $(128)$ & (94) \\
\hline observations with missing information for & & \\
\hline market related data (ask/hi price and bid/lo price) & $(127)$ & $(40)$ \\
\hline Total sample & 1,154 & 824 \\
\hline "Other Exit Activities" sample & 300 & 250 \\
\hline Restructuring sample & 854 & 574 \\
\hline
\end{tabular}

This table provides the sample selection procedures.

Our restructuring announcement data ranges from January 2010 through December 2017, with the latest restructuring

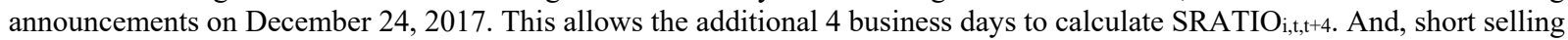
data from as early as August 15, 2009 are required for the 90-day (weekday) benchmark period before the announcement date. 
TABLE 1 (continued)

Panel B: Restructuring Distribution Across Industries and Restructuring Type

\begin{tabular}{|c|c|c|c|c|c|c|}
\hline \multirow[b]{2}{*}{ Industry Classification } & \multicolumn{2}{|c|}{$\begin{array}{c}\text { Full } \\
\text { Sample }\end{array}$} & \multicolumn{2}{|c|}{$\begin{array}{c}\text { Cost } \\
\text { Restructuring }\end{array}$} & \multicolumn{2}{|c|}{$\begin{array}{c}\text { Asset } \\
\text { Restructuring }\end{array}$} \\
\hline & $\underline{\mathbf{n}}$ & $\underline{\%}$ & $\underline{\mathbf{n}}$ & $\%$ & $\underline{\mathbf{n}}$ & $\%$ \\
\hline 1.Consumer NonDurables & 52 & 6.09 & 8 & 2.77 & 44 & 7.79 \\
\hline 2. Consumer Durables & 40 & 4.68 & 4 & 1.38 & 36 & 6.37 \\
\hline 3. Manufacturing & 118 & 13.82 & 23 & 7.96 & 95 & 16.81 \\
\hline 4. Oil, Gas, and Coal & 11 & 1.29 & 3 & 1.04 & 8 & 1.42 \\
\hline 5. Chemicals and Allied Products & 48 & 5.62 & 4 & 1.38 & 44 & 7.79 \\
\hline 6. Business Equipment & 286 & 33.49 & 121 & 41.87 & 165 & 29.20 \\
\hline 7. Telephone and Television & 10 & 1.17 & 4 & 1.38 & 6 & 1.06 \\
\hline 8. Utilities & 10 & 1.17 & 2 & 0.69 & 8 & 1.42 \\
\hline 9. Wholesale and Retail & 60 & 7.03 & 13 & 4.50 & 47 & 8.32 \\
\hline 10. Healthcare & 156 & 18.27 & 84 & 29.07 & 72 & 12.74 \\
\hline 11. Other & 63 & 7.38 & 23 & 7.96 & 40 & 7.08 \\
\hline Total & 854 & $100 \%$ & 289 & $100 \%$ & 565 & $100 \%$ \\
\hline
\end{tabular}

The industry distribution is based on the Fama-French 12-industry distribution, excluding the Money-Finance industry (6000-6999).

Panel C: Restructuring Distribution Across Reasons and Savings Disclosure

\begin{tabular}{|c|c|c|c|c|c|c|c|}
\hline \multirow[b]{2}{*}{ Reasons: } & & \multicolumn{2}{|c|}{$\begin{array}{c}\text { Full } \\
\text { Sample }\end{array}$} & \multicolumn{2}{|c|}{$\begin{array}{c}\text { Cost } \\
\text { Restructuring }\end{array}$} & \multicolumn{2}{|c|}{$\begin{array}{c}\text { Asset } \\
\text { Restructuring }\end{array}$} \\
\hline & & $\underline{\mathrm{n}}$ & $\%$ & $\underline{\mathbf{n}}$ & $\%$ & $\underline{\mathbf{n}}$ & $\%$ \\
\hline & (1) Align cost Structure & 362 & $42.39 \%$ & 171 & $59.17 \%$ & 191 & $33.81 \%$ \\
\hline & (2) Challenging Industry/Competition & 88 & $10.30 \%$ & 23 & $7.96 \%$ & 65 & $11.50 \%$ \\
\hline & (3) Focus Core & 63 & $7.38 \%$ & 15 & $5.19 \%$ & 48 & $8.50 \%$ \\
\hline & (4) Low Profit/Underperformance & 28 & $3.28 \%$ & 4 & $1.38 \%$ & 24 & $4.25 \%$ \\
\hline & (5) Others & 25 & $2.93 \%$ & 7 & $2.42 \%$ & 18 & $3.19 \%$ \\
\hline & (6) No Reason Disclosed & 288 & $33.72 \%$ & 69 & $23.88 \%$ & 219 & $38.76 \%$ \\
\hline & Total & 854 & $100 \%$ & 289 & $100 \%$ & 565 & $100 \%$ \\
\hline \multicolumn{8}{|l|}{ Savings : } \\
\hline & (1) Cost Savings Disclosed & 346 & $40.52 \%$ & 127 & $43.94 \%$ & 219 & $38.76 \%$ \\
\hline & (2) Cost Savings Not Disclosed & 508 & $59.48 \%$ & 162 & $56.06 \%$ & 346 & $61.24 \%$ \\
\hline & Total & 854 & $100 \%$ & 289 & $100 \%$ & 565 & $100 \%$ \\
\hline
\end{tabular}

This table reports reasons disclosed in the restructuring announcements and presents reasons across two restructuring types. Then, the table reports restructuring announcements by whether the announcement discloses information related to the future or current cost savings. Here, 'cost savings not disclosed' indicates that the announcement does not explicitly mention cost savings. 
TABLE 2

Panel A: Descriptive Statistics for Full Sample

\begin{tabular}{|c|c|c|c|c|c|c|c|c|c|c|c|}
\hline \multicolumn{6}{|c|}{ Event Day $[t=0]$} & \multicolumn{5}{|c|}{ Non-Event Days [t-100 through t-11] } & \multirow{3}{*}{$\frac{\text { Mean }}{\text { Difference }}$} \\
\hline & & & 25th & & 75th & & & 25th & & 75th & \\
\hline Variable & $\underline{\text { Mean }}$ & $\underline{\text { St. dev }}$ & percentile & $\underline{\text { Median }}$ & percentile & Mean & $\underline{\text { St. dev }}$ & percentile & $\underline{\text { Median }}$ & percentile & \\
\hline SRATIO $_{i, t}$ & 0.191 & 0.282 & 0.033 & 0.084 & 0.199 & 0.144 & 0.213 & 0.031 & 0.071 & 0.159 & $0.047^{* * *}$ \\
\hline RAWRET $_{i, t}$ & -0.002 & 0.047 & -0.015 & 0.000 & 0.013 & -0.001 & 0.039 & -0.013 & 0.000 & 0.012 & -0.001 \\
\hline $\operatorname{VRET}_{i, t}$ & 0.000 & 0.010 & -0.004 & 0.001 & 0.005 & 0.000 & 0.010 & -0.004 & 0.001 & 0.005 & -0.000 \\
\hline PVOLT $_{i, t}$ & 0.042 & 0.031 & 0.021 & 0.033 & 0.055 & 0.037 & 0.027 & 0.018 & 0.029 & 0.045 & $0.006 * * *$ \\
\hline TURNOVER $_{i, t}$ & 1.278 & 1.481 & 0.393 & 0.755 & 1.457 & 1.014 & 1.144 & 0.351 & 0.657 & 1.207 & $0.264 * * *$ \\
\hline PRICE $_{i, t}$ & 25.192 & 30.913 & 5.080 & 15.125 & 34.970 & 25.192 & 30.803 & 5.390 & 14.960 & 34.500 & 0.000 \\
\hline $\mathrm{ASK} / \mathrm{HIGH}_{\mathrm{i}, \mathrm{t}}$ & 25.590 & 31.320 & 5.140 & 15.438 & 35.710 & 25.526 & 31.101 & 5.520 & 15.220 & 34.950 & 0.064 \\
\hline $\mathrm{BID} / \mathrm{LO}_{\mathrm{i}, \mathrm{t}}$ & 24.803 & 30.428 & 4.790 & 14.800 & 34.480 & 24.882 & 30.478 & 5.270 & 14.730 & 34.040 & -0.079 \\
\hline
\end{tabular}

This table reports summary statistics of market data and short selling data for the sample of 854 restructuring announcements. We present summary statistics for event days $(854)(\mathrm{t}=0)$ and for the 90 -day benchmark period.

Final column reports results of tests of mean differences between Event day and benchmark period.

$*, * *, * * *$ denote statistical significance at the $0.10,0.05$, and the 0.01 levels.

Variable definitions appear in Appendix I. 
TABLE 2 (Continued)

Panel B: Descriptive Statistics by Restructuring Type

\begin{tabular}{|c|c|c|c|c|c|c|c|c|c|c|}
\hline \multirow{3}{*}{ Variables } & & \multicolumn{3}{|c|}{$\begin{array}{c}\text { Cost } \\
\text { Restructuring (a) }\end{array}$} & \multicolumn{3}{|c|}{$\begin{array}{c}\text { Asset } \\
\text { Restructuring (b) }\end{array}$} & \multirow{2}{*}{$\begin{array}{c}\begin{array}{c}\text { Mean } \\
\text { Diffe re nce }\end{array} \\
\mathbf{a - b} \\
\end{array}$} \\
\hline & $\underline{\mathbf{N}}$ & Mean & Full Sample & \multicolumn{3}{|c|}{ N Mean Median } & \multicolumn{3}{|c|}{$\underline{N}$ Mean Median } & \\
\hline & & & & & & & & & & \\
\hline SRATIO $_{i, t}$ & 854 & 0.191 & 0.084 & 289 & 0.221 & 0.096 & 565 & 0.176 & 0.081 & $0.044 * *$ \\
\hline $\mathrm{ABSS}_{\mathrm{i}, \mathrm{t}}$ & 753 & 0.380 & -0.149 & 243 & 0.465 & -0.202 & 510 & 0.340 & -0.126 & 0.125 \\
\hline SRATIO $_{\mathrm{i}, \mathrm{t}, \mathrm{t}+4}$ & 854 & 0.201 & 0.114 & 289 & 0.232 & 0.130 & 565 & 0.185 & 0.106 & $0.047 * * *$ \\
\hline SRATIO $_{\mathrm{i}, \mathrm{t}-\mathrm{s}, \mathrm{t}-1}$ & 854 & 0.144 & 0.080 & 289 & 0.173 & 0.088 & 565 & 0.129 & 0.075 & $0.044 * * *$ \\
\hline $\mathrm{ABSS}_{\mathrm{i}, \mathrm{t}, \mathrm{t}+4}$ & 753 & 0.615 & 0.113 & 243 & 0.712 & 0.117 & 510 & 0.569 & 0.112 & 0.143 \\
\hline \multicolumn{11}{|l|}{ Market Related: } \\
\hline RAWRET $_{i, t}$ & 854 & -0.002 & 0.000 & 289 & -0.001 & 0.000 & 565 & -0.002 & 0.000 & 0.001 \\
\hline $\operatorname{VRET}_{i, t}$ & 854 & 0.000 & 0.001 & 289 & -0.000 & 0.000 & 565 & 0.001 & 0.001 & -0.001 \\
\hline PVOLT $_{i, t}$ & 854 & 0.042 & 0.033 & 289 & 0.048 & 0.038 & 565 & 0.039 & 0.030 & $0.008 * * *$ \\
\hline TURNOVER $_{\mathrm{i}, \mathrm{t}}$ & 854 & 1.278 & 0.755 & 289 & 1.397 & 0.782 & 565 & 1.217 & 0.724 & $0.180 *$ \\
\hline PRICE $_{\mathrm{i}, \mathrm{t}}$ & 854 & 25.192 & 15.125 & 289 & 17.073 & 7.410 & 565 & 29.345 & 19.530 & $-12.272 * * *$ \\
\hline ASKHIGH $_{\mathrm{i}, \mathrm{t}}$ & 854 & 25.590 & 15.438 & 289 & 17.407 & 7.600 & 565 & 29.776 & 19.740 & $-12.369 * * *$ \\
\hline BIDLO $_{\mathrm{i}, \mathrm{t}}$ & 854 & 24.803 & 14.800 & 289 & 16.758 & 7.300 & 565 & 28.919 & 19.130 & $-12.161 * * *$ \\
\hline $\mathrm{ABVOL}_{\mathrm{i}, \mathrm{t}}$ & 753 & 0.309 & -0.031 & 243 & 0.409 & -0.037 & 510 & 0.262 & -0.030 & 0.147 \\
\hline $\mathrm{RET}_{\mathrm{i}, \mathrm{t}, \mathrm{t}+4}$ & 854 & -0.009 & -0.007 & 289 & -0.014 & -0.014 & 565 & -0.006 & -0.004 & -0.008 \\
\hline $\operatorname{RET}_{\mathrm{i}, \mathrm{t}-5, \mathrm{t}-1}$ & 854 & -0.003 & -0.002 & 289 & -0.004 & -0.006 & 565 & -0.002 & -0.001 & -0.002 \\
\hline $\mathrm{PVOLT}_{\mathrm{i}, \mathrm{t}, \mathrm{t}+4}$ & 854 & 0.044 & 0.038 & 289 & 0.050 & 0.043 & 565 & 0.041 & 0.033 & $0.009 * * *$ \\
\hline $\operatorname{PVOLT}_{\mathrm{i}, \mathrm{t}-\mathrm{s}, \mathrm{t}-1}$ & 854 & 0.038 & 0.031 & 289 & 0.044 & 0.039 & 565 & 0.034 & 0.028 & $0.010 * * *$ \\
\hline TURNOVER $_{\mathrm{i}, \mathrm{t}-5, \mathrm{t}-1}$ & 854 & 1.021 & 0.710 & 289 & 1.159 & 0.771 & 565 & 0.951 & 0.690 & $0.208 * * *$ \\
\hline $\mathrm{ABVOL}_{\mathrm{i}, \mathrm{t}, \mathrm{t}+4}$ & 753 & 0.522 & 0.123 & 243 & 0.620 & 0.079 & 510 & 0.475 & 0.145 & 0.144 \\
\hline $\mathrm{CAR}_{\mathrm{i}, \mathrm{t}, \mathrm{t}+4}$ & 753 & -0.015 & -0.007 & 243 & -0.018 & -0.012 & 510 & -0.013 & -0.005 & -0.005 \\
\hline $\mathrm{CAR}_{\mathrm{i}, \mathrm{t}-5, \mathrm{t}-1}$ & 753 & -0.004 & -0.001 & 243 & -0.008 & -0.005 & 510 & -0.003 & -0.001 & -0.006 \\
\hline $\mathrm{CAR}_{\mathrm{i}, \mathrm{t}+5, \mathrm{t}+14}$ & 753 & 0.004 & 0.002 & 243 & 0.004 & 0.002 & 510 & 0.005 & 0.002 & -0.001 \\
\hline $\mathrm{CAR}_{\mathrm{i}, \mathrm{t}+5, \mathrm{t}+34}$ & 753 & -0.000 & 0.001 & 243 & -0.009 & -0.010 & 510 & 0.004 & 0.004 & -0.012 \\
\hline $\mathrm{CAR}_{\mathrm{i}, \mathrm{t}+5, \mathrm{t}+64}$ & 753 & 0.005 & 0.005 & 243 & -0.006 & -0.002 & 510 & 0.011 & 0.007 & -0.017 \\
\hline $\mathrm{CAR}_{\mathrm{i}, \mathrm{t}+5, \mathrm{t}+94}$ & 753 & 0.011 & 0.018 & 243 & 0.005 & 0.017 & 510 & 0.014 & 0.019 & -0.009 \\
\hline \multicolumn{11}{|c|}{ Firm Characteristics Related: } \\
\hline PRIORBM & 753 & 0.561 & 0.483 & 243 & 0.498 & 0.383 & 510 & 0.591 & 0.514 & $-0.093 * * *$ \\
\hline PRIORSIZE & 753 & 7.087 & 7.039 & 243 & 6.737 & 6.413 & 510 & 7.253 & 7.268 & $-0.516 * * *$ \\
\hline PRIORLOSS & 753 & 0.220 & 0.000 & 243 & 0.379 & 0.000 & 510 & 0.145 & 0.000 & $0.234 * * *$ \\
\hline RESTRCOST & 702 & 0.020 & 0.012 & 231 & 0.015 & 0.009 & 471 & 0.023 & 0.013 & $-0.007 * * *$ \\
\hline
\end{tabular}

This table reports descriptive statistics for full sample, and for two types of restructuring announcements. Final column reports results of tests of mean differences between mean measures for Cost restructurings and for Asset restructurings. $*, * *, * * *$ denote statistical significance at the $0.10,0.05$, and the 0.01 levels, respectively for the $\mathrm{t}$ statistics.

Variable definitions appear in Appendix I. 
Table 2 (Continued) Panel C: Descriptive Statistics across Restructuring Reason Disclosure

\begin{tabular}{|c|c|c|c|c|c|c|c|c|c|c|c|c|}
\hline \multirow[b]{4}{*}{ Variable } & \multicolumn{10}{|c|}{ Reason Disclosed } & \multirow{2}{*}{\multicolumn{2}{|c|}{$\begin{array}{c}\text { Reason } \\
\text { Not } \\
\text { Disclosed } \\
\end{array}$}} \\
\hline & \multicolumn{2}{|c|}{$\begin{array}{l}\text { Align Cost } \\
\text { Structure }\end{array}$} & \multicolumn{2}{|c|}{$\begin{array}{c}\text { Low Profit/ } \\
\text { Underperformance }\end{array}$} & \multicolumn{2}{|c|}{$\begin{array}{c}\text { Challenging Industry } \\
\text { /Competition }\end{array}$} & \multicolumn{2}{|c|}{ Focus Core } & \multicolumn{2}{|c|}{ Other } & & \\
\hline & \multicolumn{2}{|c|}{$[1]$} & \multicolumn{2}{|c|}{ [2] } & \multicolumn{2}{|c|}{ [3] } & \multicolumn{2}{|c|}{ [4] } & \multicolumn{2}{|c|}{ [5] } & \multicolumn{2}{|c|}{ [6] } \\
\hline & $\underline{\mathbf{N}}$ & Mean & $\underline{\mathbf{N}}$ & Mean & $\underline{\mathbf{N}}$ & Mean & $\underline{\mathbf{N}}$ & Mean & $\underline{\mathbf{N}}$ & Mean & $\underline{\mathbf{N}}$ & Mean \\
\hline SRATIO $_{i, t}$ & 362 & 0.190 & 28 & 0.245 & 88 & 0.169 & 63 & 0.236 & 25 & $\overline{0.200}$ & $2 \overline{88}$ & 0.184 \\
\hline SRATIO $_{i, t, t+4}$ & 362 & 0.205 & 28 & 0.226 & 88 & 0.170 & 63 & 0.237 & 25 & 0.155 & 288 & 0.199 \\
\hline SRATIO $_{i, t-5, t-1}$ & 362 & 0.143 & 28 & 0.169 & 88 & 0.141 & 63 & 0.172 & 25 & 0.124 & 288 & 0.139 \\
\hline RAWRET $_{\mathrm{i}, \mathrm{t}}$ & 362 & -0.002 & 28 & -0.001 & 88 & -0.009 & 63 & -0.011 & 25 & -0.017 & 288 & 0.004 \\
\hline $\operatorname{VRET}_{i, t}$ & 362 & 0.000 & 28 & 0.002 & 88 & 0.000 & 63 & -0.002 & 25 & -0.001 & 288 & 0.001 \\
\hline $\mathrm{RET}_{\mathrm{i}, \mathrm{t}, \mathrm{t}+4}$ & 362 & -0.009 & 28 & -0.006 & 88 & -0.019 & 63 & -0.018 & 25 & -0.016 & 288 & -0.004 \\
\hline $\operatorname{RET}_{\mathrm{i}, \mathrm{t}-\mathrm{-}, \mathrm{t}-1}$ & $\underline{362}$ & -0.004 & $\underline{28}$ & -0.013 & $\underline{88}$ & 0.000 & $\underline{63}$ & 0.002 & $\underline{25}$ & -0.011 & $\underline{288}$ & -0.001 \\
\hline Freq & $42.4 \%$ & & $3.3 \%$ & & $10.3 \%$ & & $7.4 \%$ & & $2.9 \%$ & & $33.7 \%$ & \\
\hline
\end{tabular}

This table reports the descriptive statistics across different reasons of restructuring as well as for no reason disclosed. Variable definitions appear in Appendix I.

Panel D: Descriptive Statistics across Cost Savings Disclosure

\begin{tabular}{|c|c|c|c|c|c|}
\hline \multirow[t]{2}{*}{ Variables } & \multicolumn{2}{|c|}{$\begin{array}{c}\text { Cost Savings Disclosed } \\
{[1]}\end{array}$} & \multicolumn{2}{|c|}{$\frac{\text { Cost Savings Not Disclosed }}{[2]}$} & \multirow{2}{*}{$\frac{[3]}{\text { Mean Diffe rence }}$} \\
\hline & $\underline{\mathbf{N}}$ & Mean & $\underline{\mathbf{N}}$ & Mean & \\
\hline SRATIO $_{i, t}$ & 346 & 0.173 & 508 & 0.204 & -0.030 \\
\hline SRATIO $_{i, t, t+4}$ & 346 & 0.179 & 508 & 0.216 & $-0.038 * *$ \\
\hline SRATIO $_{\mathrm{i}, \mathrm{t}-5, \mathrm{t}-1}$ & 346 & 0.129 & 508 & 0.154 & $-0.025 *$ \\
\hline RAWRET $_{\mathrm{i}, \mathrm{t}}$ & 346 & -0.001 & 508 & -0.002 & 0.001 \\
\hline $\operatorname{VRET}_{\mathrm{i}, \mathrm{t}}$ & 346 & 0.001 & 508 & 0.000 & 0.001 \\
\hline $\operatorname{RET}_{i, t, t+4}$ & 346 & -0.009 & 508 & -0.009 & -0.001 \\
\hline $\operatorname{RET}_{\mathrm{i}, \mathrm{t}-5, \mathrm{t}-1}$ & 346 & -0.001 & 508 & -0.004 & 0.003 \\
\hline
\end{tabular}

This table presents summary statistics for announcement mentioning cost savings and no savings information. *,**,*** denotes statistical significance at the 0.10 , 0.05 , and the 0.01 levels, respectively for the t statistics. Variable definitions appear in Appendix I. 


\section{TABLE 3}

\section{Hypothesis 1}

\section{Short Ratio and Excess Return on Days Surrounding the Restructuring Announcement Date}

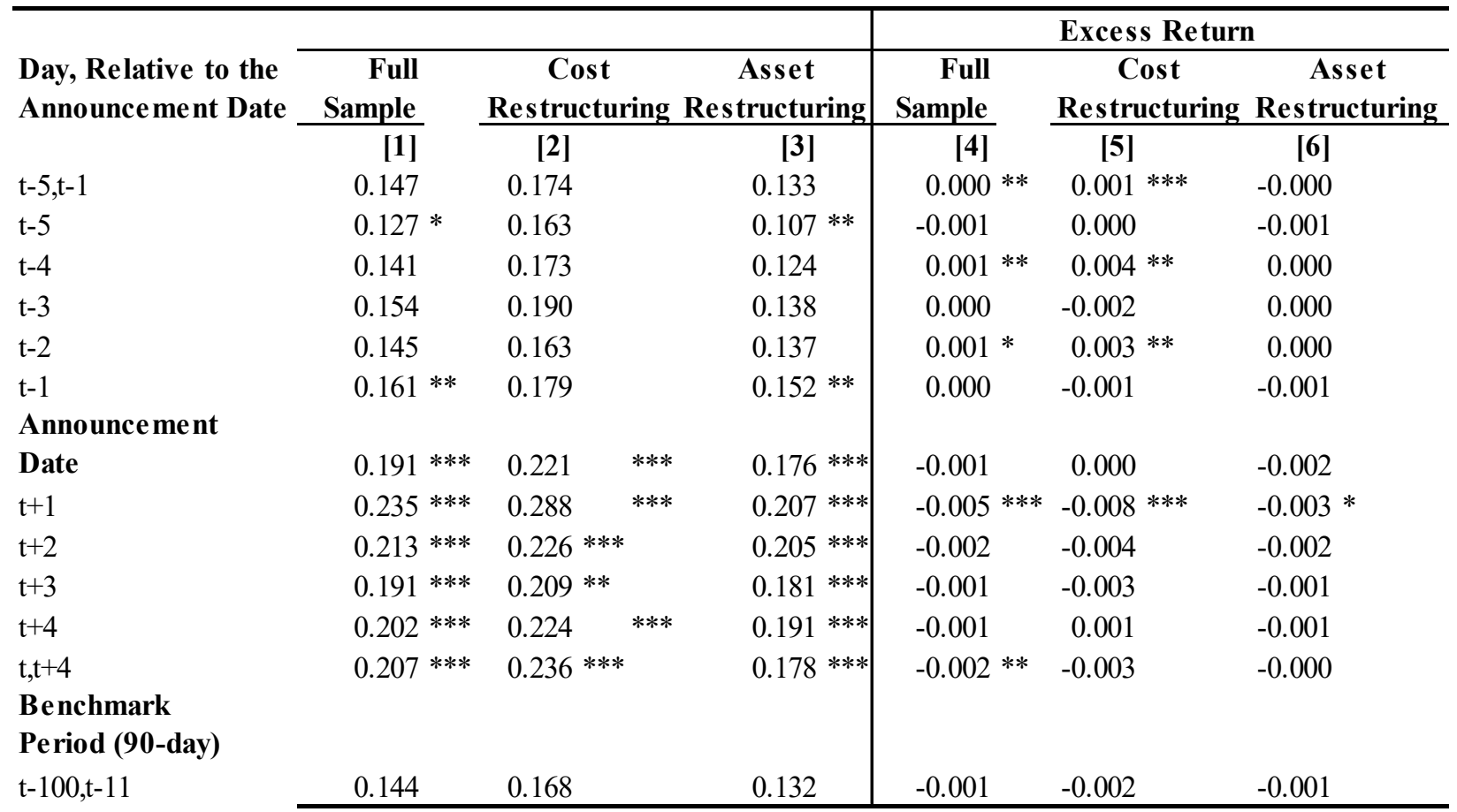

This table reports the results of an event study of short sellers' reactions (market reactions) surrounding restructuring announcements.

We analyze 854 announcements for the full sample (289 for cost restructuring, and 565 for asset restructuring).

We compare the Short Ratio (Excess Return) of each window with those of the benchmark period. Following Drake et al. (2015), we estimate a 90-day benchmark period that ends 10 days before the restructuring announcement (the benchmark period starts from $\mathrm{t}-100$ and ends on $\mathrm{t}-11$ ).

The reported t-test compares the observed Short Ratio (Excess Return) from the days surrounding the restructuring announcements to the same measure the benchmark period.

$*, * *, * * *$ denote statistical significance at the $0.10,0.05$, and 0.01 levels, respectively. They reflect a test the Short Ratio (Excess Return) for each day (or window of days) against the benchmark period.

Variable definitions appear in Appendix I. 
TABLE 4

Correlation Matrix (Spearman above/Pearson below)

$$
(\mathbf{n}=\mathbf{8 5 4})
$$

\begin{tabular}{|c|c|c|c|c|c|c|c|c|}
\hline Variables & (1) & $(2)$ & (3) & (4) & (5) & (6) & & (7) \\
\hline (1) SRATIO $_{i, t, t+4}$ & & $\overline{-0.047}$ & 0.009 & $0.778 * * *$ & $\overline{0.221} * * *$ & 0.072 & $* *$ & $\overline{0.761} * * *$ \\
\hline (2) $\mathrm{RET}_{\mathrm{i}, \mathrm{t}, \mathrm{t}+4}$ & $-0.084 * *$ & & -0.024 & -0.025 & $-0.144 * * *$ & -0.091 & $* * *$ & -0.015 \\
\hline (3) $\mathrm{RET}_{\mathrm{i}, \mathrm{t}-5, \mathrm{t}-1}$ & -0.043 & -0.000 & & $0.065 *$ & $-0.096 * * *$ & -0.086 & $* *$ & 0.027 \\
\hline (4) SRATIO $_{i, t-5, t-1}$ & $0.791 * * *$ & $-0.064 *$ & $-0.059 *$ & & $0.080 * *$ & 0.135 & $* * *$ & $0.908 * * *$ \\
\hline (5) $\mathrm{PVOLT}_{\mathrm{i}, \mathrm{t}, \mathrm{t}+4}$ & $0.269 * * *$ & $-0.156 * * *$ & $-0.080 * *$ & $0.180 * * *$ & & 0.791 & $* * *$ & 0.016 \\
\hline (6) $\operatorname{PVOLT}_{i, t-5, t-1}$ & $0.182 * * *$ & $-0.143 * * *$ & $-0.058 *$ & $0.313 * * *$ & $0.746 * * *$ & & & $0.078 * *$ \\
\hline (7) TURNOVER TUt, $-5, t-1$ & $0.784 * * *$ & -0.053 & $-0.081 * *$ & $0.931 * * *$ & $0.146 * * *$ & 0.279 & $* * *$ & \\
\hline
\end{tabular}

This table provides correlations among the variables used in multivariate analysis of the event study. $*, * *, * * *$ denote statistical significance at the $0.10,0.05$, and the 0.01 levels, respectively.

Variable definitions appear in Appendix I. 
TABLE 5: Panel A: Hypothesis 2Main

Regression Results of Short Ratio (SRATIO) on Restructuring Announcement (DUMMYREST $\mathrm{i}_{\mathrm{i}, \mathrm{t}}$

\begin{tabular}{|c|c|c|}
\hline Dependent Variable & SRATIO $_{\mathrm{i}, \mathrm{t}, \mathrm{t}+4}$ & SRATIO $_{i, t, t+4}$ \\
\hline & [1] & [2] \\
\hline \multirow[t]{2}{*}{$\operatorname{DUMMYREST}_{i, t}$} & $0.028 * * *$ & $0.033 * * *$ \\
\hline & {$[6.66]$} & {$[7.70]$} \\
\hline \multirow[t]{2}{*}{$\operatorname{RET}_{i, t, t+4}$} & $0.077 * * *$ & $0.19 * * *$ \\
\hline & {$[3.27]$} & [17.51] \\
\hline \multirow[t]{2}{*}{$\operatorname{RET}_{\mathrm{i}, \mathrm{t}-\mathrm{5}, \mathrm{t}-1}$} & 0.007 & 0.003 \\
\hline & {$[0.39]$} & {$[0.52]$} \\
\hline \multirow[t]{2}{*}{ SRATIO $_{i, t-5, t-1}$} & $0.322 * * *$ & $0.509 * * *$ \\
\hline & {$[9.32]$} & {$[25.21]$} \\
\hline \multirow[t]{2}{*}{$\operatorname{PVOLT}_{i, t, t+4}$} & $3.865 * * *$ & $3.726 * * *$ \\
\hline & [17.46] & [25.83] \\
\hline \multirow[t]{2}{*}{ PVOLT $_{\mathrm{i}, \mathrm{t}-5, \mathrm{t}-1}$} & $-1.687 * * *$ & $-2.361 * * *$ \\
\hline & {$[-10.33]$} & {$[-22.26]$} \\
\hline \multirow[t]{2}{*}{ TURNOVER $_{\mathrm{i}, \mathrm{t}-5, \mathrm{t}-1}$} & $0.034 * * *$ & $0.033 * * *$ \\
\hline & {$[6.17]$} & [11.62] \\
\hline \multirow[t]{2}{*}{ Intercept } & $-0.016 * *$ & $-0.012 * * *$ \\
\hline & {$[-2.11]$} & {$[-4.31]$} \\
\hline Adj. $R^{2}$ & 0.78 & 0.75 \\
\hline Stock Fixed Effects & YES & YES \\
\hline Day Fixed Effects & YES & YES \\
\hline $\mathrm{N}$ (event days) & 854 & 854 \\
\hline N (non event days) & 54,835 & $1,667,484$ \\
\hline $\mathrm{N}=$ Total & 55,689 & $1,668,338$ \\
\hline
\end{tabular}

This table reports regression results from the equation below, with t-statistics reported in brackets [ ].

$S_{R A T I O}^{i, t, t+4}=\beta_{0}+\beta_{1}$ DUMMYREST $_{i, t}+\beta_{2}$ RET $_{i, t, t+4}+\beta_{3}$ RET $_{i, t-5, t-1}+\beta_{4}$ SRATIO $_{i, t-5, t-1}+\beta_{5}$ PVOLT $_{i, t, t+4}+\beta_{6}$ PVOLT Ti,t-5,t-1 $_{1}+\beta_{7}$ TURNOVER $_{i, t-5, t-1}+\varepsilon$

In column [1], DUMMYREST $T_{i, t}$ equals 1 if the day is the event day/restructuring announcement day, 0 if it is any day in the benchmark period (t-100 through $\mathrm{t}-11)$.

In column [2], DUMMYREST $T_{i, t}$ equals 1 if the day is the event day/restructuring announcement day, 0 if it is any day in the non-event day in the full sample.

A Hausman test rejects the presence of random effects.

$*, * *, * * *$ denotes statistical significance at the $0.10,0.05$, and the 0.01 levels, respectively.

Other variable definitions except DUMMYREST $T_{i, t}$ appear in Appendix I. 
Table 5 (continued): Panel B: Hypothesis 2A: Regression Results of Daily Short Ratio (SRATIO) on Restructuring Announcement Across Cost Restructuring and Asset Restructuring

\begin{tabular}{|c|c|c|c|c|}
\hline \multirow[t]{3}{*}{ Dependent Variable } & SRATIO $_{\mathrm{i}, \mathrm{t}, \mathrm{t}+4}$ & SRATIO $_{i, t, t+4}$ & SRATIO $_{i, t, t+4}$ & SRATIO $_{i, t, t+4}$ \\
\hline & $\begin{array}{r}\text { Cost } \\
\text { Restructuring }\end{array}$ & $\begin{array}{r}\text { Asset } \\
\text { Restructuring }\end{array}$ & $\begin{array}{r}\text { Cost } \\
\text { Restructuring }\end{array}$ & $\begin{array}{r}\text { Asset } \\
\text { Restructuring }\end{array}$ \\
\hline & {$[1]$} & {$[2]$} & [3] & [4] \\
\hline \multirow[t]{2}{*}{ DUMMYREST $_{\mathrm{i}, \mathrm{t}}$} & $0.032 * * *$ & $0.025 * * *$ & $0.038 * * *$ & $0.030 * * *$ \\
\hline & {$[3.88]$} & [4.98] & [4.79] & {$[6.40]$} \\
\hline CONTROLS & YES & YES & YES & YES \\
\hline Adj. $R^{2}$ & 0.80 & 0.77 & 0.75 & 0.74 \\
\hline Stock Fixed Effects & YES & YES & YES & YES \\
\hline Day Fixed Effects & YES & YES & YES & YES \\
\hline $\mathrm{N}$ (event days) & 289 & 565 & 289 & 565 \\
\hline $\mathrm{N}$ (non event days) & 18,362 & 36,473 & 522,674 & $1,144,810$ \\
\hline $\mathrm{N}=$ Total & 18,651 & 37,038 & 522,963 & $1,145,375$ \\
\hline \multicolumn{3}{|c|}{$\begin{array}{l}\text { Testing the Equality of Coefficient between Cost and Asset Restructuring } \\
\qquad \text { F-statistic (p-value) }=0.90(0.342)\end{array}$} & \multicolumn{2}{|c|}{$\begin{array}{l}\text { between Cost and Asset Restructuring } \\
\text { F-statistic (p-value) }=0.55(0.460)\end{array}$} \\
\hline \multicolumn{5}{|c|}{ 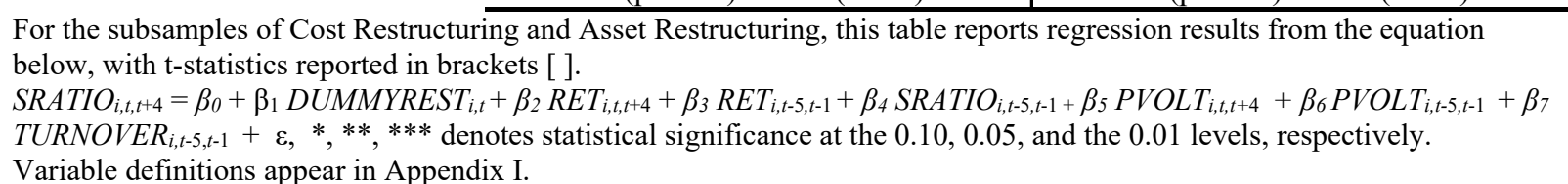 } \\
\hline
\end{tabular}

Table 5 (continued): Panel C: Hypothesis 2B: Regression Results of Abnormal Short Ratio (ABSS) on Restructuring Cost (RESTCOST)

\begin{tabular}{|c|c|c|c|}
\hline Dependent Variable & $\begin{array}{c}\text { ABSS }_{\mathrm{i}, \mathrm{t}, \mathrm{t}+4} \\
\text { Full } \\
\text { Sample }\end{array}$ & $\begin{array}{c}\text { ABSS }_{\mathrm{i}, \mathrm{t}, \mathrm{t}+4} \\
\text { Cost } \\
\text { Restructuring }\end{array}$ & $\begin{array}{c}\text { ABSS }_{\mathrm{i}, \mathrm{t}, \mathrm{t}+\mathbf{4}} \\
\text { Asset } \\
\text { Res tructuring }\end{array}$ \\
\hline & [1] & {$[2]$} & [3] \\
\hline & Coef & Coef & Coef \\
\hline \multirow[t]{2}{*}{$\operatorname{RESTRCOST}_{i, t}$} & 1.22 & $6.057 * *$ & -0.329 \\
\hline & {$[0.88]$} & {$[2.37]$} & {$[-0.19]$} \\
\hline CONTROLS & Yes & Yes & Yes \\
\hline Industry Fixed Effects & Yes & Yes & Yes \\
\hline Year Fixed Effects & Yes & Yes & Yes \\
\hline Observations & 702 & 231 & 471 \\
\hline Adj. $R^{2}$ & 0.73 & 0.87 & 0.58 \\
\hline \multicolumn{2}{|c|}{ Testing the Equality of Coefficient } & \multicolumn{2}{|c|}{$\begin{array}{l}\text { between Cost and Asset Restructuring } \\
\text { F-statistic (p-value) }=4.86(0.028)\end{array}$} \\
\hline \multicolumn{4}{|c|}{ 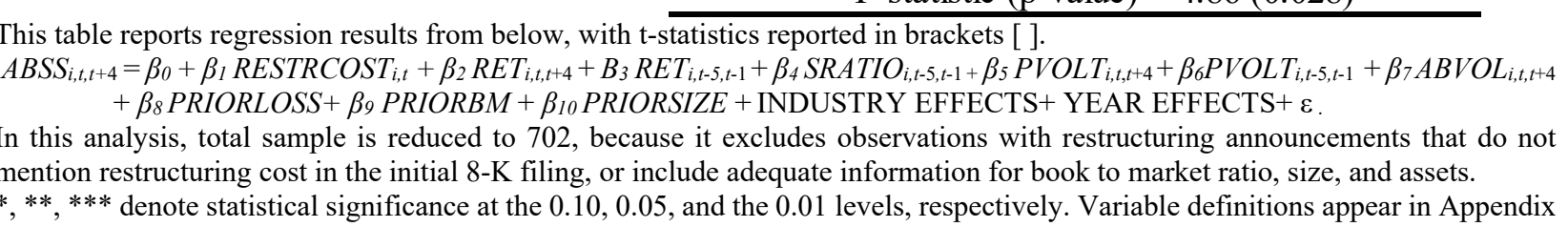 } \\
\hline
\end{tabular}


TABLE 5 (continued)

Panel D: Hypothesis 2C: Full Sample of Restructuring Announcements and Sample of Other Exit Announcements

\begin{tabular}{|c|c|c|c|c|}
\hline \multirow[t]{2}{*}{ Dependent Variable } & \multirow{2}{*}{$\begin{array}{l}\text { SRATIO }_{\mathrm{i}, \mathrm{t}, \mathrm{t}+4} \\
\text { Restructuring }\end{array}$} & \multirow{2}{*}{$\begin{array}{r}\text { SRATIO }_{\mathrm{i}, \mathrm{t}, \mathrm{t}+4} \\
\text { Other Exit }\end{array}$} & \multicolumn{2}{|c|}{ SRATIO $_{i, t, t+4}$ SRATIO $_{i, t, t+4}$} \\
\hline & & & Res tructuring & Other Exit \\
\hline & {$[1]$} & [2] & [3] & [4] \\
\hline \multirow{2}{*}{ DUMMYREST $_{i, t}$} & $0.028 * * *$ & 0.014 & $0.033 * * *$ & $0.014 * * *$ \\
\hline & {$[6.66]$} & {$[1.28]$} & {$[7.70]$} & {$[2.03]$} \\
\hline CONTROLS & YES & YES & YES & YES \\
\hline $\operatorname{Adj} . R^{2}$ & 0.78 & 0.80 & 0.75 & 0.74 \\
\hline Stock FE & YES & YES & YES & YES \\
\hline Day FE & YES & YES & YES & YES \\
\hline $\mathrm{N}$ (event days) & 854 & 300 & 854 & 300 \\
\hline $\mathrm{N}$ (non event days) & 54,835 & 19,228 & $1,667,484$ & 593,463 \\
\hline $\mathrm{N}=$ Total & 55,689 & 19,528 & $1,668,338$ & 593,763 \\
\hline $\begin{array}{l}\text { Test for the Equality } \\
\text { of Coefficient }\end{array}$ & \multicolumn{2}{|c|}{$\begin{array}{l}\text { between Cost and Asset Restructuring } \\
\text { F-statistic ( } p \text {-value })=4.98(0.026)\end{array}$} & \multicolumn{2}{|c|}{$\begin{array}{l}\text { between Cost and Asset Restructuring } \\
\text { F-statistic (p-value) }=5.55(0.019)\end{array}$} \\
\hline
\end{tabular}

This table compares the short interest for explicit restructuring announcements with other exit activities announcements using the equation below with t-statistics reported in brackets [ ].

$S_{R A T I O} i, t, t+4=\beta_{0}+\beta_{1}$ DUMMYREST $_{i, t}+\beta_{2}$ RET $_{i, t, t+4}+\beta_{3} \operatorname{RET}_{i, t-5, t-1}+\beta_{4}$ SRATIO $_{i, t-5, t-1}+\beta_{5}$ PVOLT $_{i, t, t+4}+\beta_{6} P V O L T_{i, t-5, t-1}+\beta_{7}$ TURNOVER $R_{i, t-5, t-1}+\varepsilon$.

Columns 1 and 3 are based on explicit restructuring announcements and columns 2 and 4 on other exit activities announcements. DUMMYREST $_{\mathrm{i}, \mathrm{t}}$ equals 1 if the day is the event day/restructuring announcement day, 0 if it is any day in the benchmark period (t-100 through $\mathrm{t}-11$ ).

Standard errors are clustered by firm and day.

$*, * *, * * *$ denotes statistical significance at the $0.10,0.05$, and the 0.01 levels, respectively.

Variable definitions appear in Appendix I. 
TABLE 5 (continued) Panel E: Sensitivity Tests

Chi Square Test (Tercile of Short Interest)

\begin{tabular}{|c|c|c|c|c|c|c|c|}
\hline \multicolumn{8}{|c|}{ Cost/Asset Restructuring and Short Interest Tercile } \\
\hline & \multicolumn{2}{|c|}{ Low } & \multicolumn{2}{|c|}{ Medium } & \multicolumn{2}{|c|}{ High } & \multirow[t]{2}{*}{ Total } \\
\hline & \# & $\overline{\%}$ & \# & $\overline{\%}$ & \# & $\%$ & \\
\hline Asset Restructuring & 200 & $35.40 \%$ & 196 & $34.69 \%$ & 169 & $29.91 \%$ & 565 \\
\hline Cost Restructuring & 84 & $29.07 \%$ & 89 & $30.80 \%$ & 116 & $40.14 \%$ & 289 \\
\hline \multirow[t]{3}{*}{ Total } & 284 & & 285 & & 285 & & 854 \\
\hline & & & & & Prob & & 0.010 \\
\hline & & & & Chi Squal & Value & & 9.167 \\
\hline \multicolumn{8}{|c|}{ Restructuring/Other Exit Activities and Short Interest Tercile } \\
\hline & \multicolumn{2}{|c|}{ Low } & \multicolumn{2}{|c|}{ Medium } & \multicolumn{2}{|c|}{ High } & Total \\
\hline & \# & $\overline{\%}$ & \# & $\overline{\%}$ & \# & $\%$ & \\
\hline Other Exit Activities & 124 & $41.33 \%$ & 94 & $31.33 \%$ & 82 & $27.33 \%$ & 300 \\
\hline Restructuirng & 260 & $30.44 \%$ & 291 & $34.07 \%$ & 303 & $35.25 \%$ & 854 \\
\hline \multirow[t]{3}{*}{ Total } & \multirow{3}{*}{\multicolumn{2}{|c|}{384}} & 385 & & \multicolumn{2}{|l|}{385} & 1154 \\
\hline & & & & & \multicolumn{2}{|l|}{ Prob } & 0.002 \\
\hline & & & & Chi Squal & Value & & 12.827 \\
\hline \multicolumn{8}{|c|}{ Reason Disclosed and not Disclosed and Short Interest Tercile } \\
\hline & \multicolumn{2}{|c|}{ Low } & \multicolumn{2}{|c|}{ Medium } & \multicolumn{2}{|c|}{ High } & Total \\
\hline & \# & $\overline{\%}$ & \# & $\overline{\%}$ & \# & $\%$ & \\
\hline Reason Disclosed & 180 & $31.80 \%$ & 202 & $35.69 \%$ & 184 & $35.21 \%$ & 566 \\
\hline Reason Not Disclosed & 104 & $36.11 \%$ & 83 & $28.82 \%$ & 101 & $35.07 \%$ & 288 \\
\hline \multirow[t]{3}{*}{ Total } & \multirow{3}{*}{\multicolumn{2}{|c|}{284}} & 285 & & \multicolumn{2}{|l|}{285} & 854 \\
\hline & & & & & \multicolumn{2}{|l|}{ Prob } & 0.126 \\
\hline & & & \multicolumn{4}{|c|}{ Chi Square Value } & 4.140 \\
\hline \multicolumn{8}{|c|}{ Savings Disclosed and Savings not Disclosed and Short Interest Tercile } \\
\hline & \multicolumn{2}{|c|}{ Low } & \multicolumn{2}{|c|}{ Medium } & \multicolumn{2}{|c|}{ High } & Total \\
\hline & \# & $\%$ & \# & $\%$ & \# & $\%$ & \\
\hline Savings Disclosed & 120 & $34.68 \%$ & 123 & $35.55 \%$ & 103 & $29.77 \%$ & 346 \\
\hline Savings Not Disclosed & 164 & $32.28 \%$ & 162 & $31.89 \%$ & 182 & $35.83 \%$ & 508 \\
\hline \multirow[t]{3}{*}{ Total } & \multirow{3}{*}{\multicolumn{2}{|c|}{284}} & 285 & & 285 & & 854 \\
\hline & & & & & Prob & & 0.179 \\
\hline & & & & Chi Squa & Value & & 3.445 \\
\hline
\end{tabular}

This table presents the tercile of short interest $\left(S R A T I O_{i, t, t+4}\right)$ across (i) Asset Restructuring and Cost Restructuring announcements (ii) across other exit announcements (exit) and explicit restructuring announcements (restructuring) (iii) across announcements in which the restructuring reason was disclosed and announcements in which no reason was disclosed, and (iv) across announcements in which the expected cost savings were disclosed and announcements in which no amount cost savings were disclosed 
TABLE 5 (continued) Panel F: Sensitivity Tests

Regression Results of Daily Short Ratio (SRATIO) on Restructuring Announcement (DUMMYREST)

\begin{tabular}{|c|c|c|c|c|}
\hline Dependent Variable & SRATIO $_{\mathrm{i}, \mathrm{t}, \mathrm{t}+4}$ & SRATIO $_{i, t, t+4}$ & SRATIO $_{i, t, t+4}$ & SRATIO $_{i, t, t+4}$ \\
\hline & $\begin{array}{l}\text { Excluding Earnings } \\
\text { Announcements }\end{array}$ & $\begin{array}{c}\text { Excluding any other } 8 \\
\text { K Content }\end{array}$ & $\begin{array}{c}\text { First-Time } \\
\text { Announcement }\end{array}$ & $\begin{array}{c}\text { Multiple } \\
\text { Announcements }\end{array}$ \\
\hline \multirow{3}{*}{ DUMMYREST $_{i, t}$} & [1] & {$[2]$} & [3] & [4] \\
\hline & $0.017 * * *$ & $0.017 * *$ & $0.032 * * *$ & $0.024 * * *$ \\
\hline & {$[3.78]$} & {$[2.79]$} & {$[5.29]$} & {$[3.83]$} \\
\hline CONTROLS & YES & YES & YES & YES \\
\hline $\operatorname{Adj} . R^{2}$ & 0.77 & 0.76 & 0.81 & 0.79 \\
\hline Stock FE & YES & YES & YES & YES \\
\hline Day FE & YES & YES & YES & YES \\
\hline $\mathrm{N}$ (event days) & 610 & 298 & 523 & 331 \\
\hline $\mathrm{N}$ (non event days) & 39,393 & 19,014 & 33,304 & 21,531 \\
\hline $\mathrm{N}=$ Total & 40,003 & 19,312 & 33,827 & 21,862 \\
\hline
\end{tabular}

This table reports the sensitivity tests based on the equation below with t-statistics reported in brackets [ ].

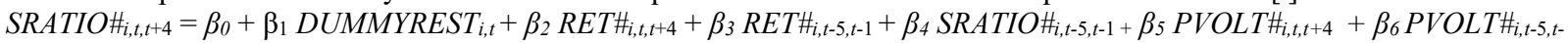
$1+\beta_{7}$ TURNOVER\# ${ }_{i, t-5, t-1}+\varepsilon$. \# indicates the variable used in the regression is averaged over five days. $*, * *, * * *$ denote statistical significance at the $0.10,0.05$, and the 0.01 levels, respectively.

Variable definitions appear in Appendix I.

TABLE 5 (continued) Panel G: Sensitivity Tests

Regression Results of Daily Short Ratio (SRATIO) on Restructuring Announcement (DUMMYREST)

\begin{tabular}{|c|c|c|c|c|}
\hline Dependent Variable & SRATIO $_{\mathrm{i}, \mathrm{t}, \mathrm{t}+4}$ & SRATIO $_{\mathrm{i}, \mathrm{t}, \mathrm{t}+4}$ & SRATIO $_{\mathrm{i}, \mathrm{t}, \mathrm{t}+4}$ & SRATIO $_{\mathrm{i}, \mathrm{t}, \mathrm{t}+4}$ \\
\hline & $\begin{array}{c}\text { Reason } \\
\text { Disclosed }\end{array}$ & $\begin{array}{c}\text { Reason Not } \\
\text { Disclosed }\end{array}$ & $\begin{array}{c}\text { Savings } \\
\text { Disclosed }\end{array}$ & $\begin{array}{c}\text { Savings Not } \\
\text { Dis closed }\end{array}$ \\
\hline & [1] & {$[2]$} & [3] & [4] \\
\hline \multirow{2}{*}{ DUMMYREST $_{i, t}$} & $0.026 * * *$ & $0.026 * * *$ & $0.020 * * *$ & $0.031 * * *$ \\
\hline & {$[5.60]$} & [3.11] & {$[3.51]$} & {$[5.22]$} \\
\hline CONTROLS & YES & YES & YES & YES \\
\hline $\operatorname{Adj} . R^{2}$ & 0.799 & 0.766 & 0.771 & 0.797 \\
\hline Stock FE & YES & YES & YES & YES \\
\hline Day FE & YES & YES & YES & YES \\
\hline $\mathrm{N}$ (event days) & 566 & 288 & 346 & 508 \\
\hline $\mathrm{N}$ (non event days) & 36,415 & 18,420 & 22,021 & 32,814 \\
\hline $\mathrm{N}=$ Total & 36,981 & 18,708 & 22,367 & 33,322 \\
\hline
\end{tabular}

This table reports the sensitivity tests based on the equation below with t-statistics reported in brackets [ ].

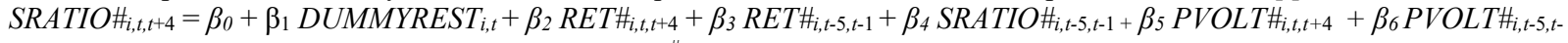
$1+\beta_{7}$ TURNOVER\# $\#_{i, t-5, t-1}+\varepsilon . \quad \quad \#$ indicates the variable used in the regression is averaged over five days.

$*, * *, * * *$ denote statistical significance at the $0.10,0.05$, and the 0.01 levels, respectively.

Variable definitions appear in Appendix I 
TABLE 6

Regression (Hypothesis 3 and 3A): Dependent Variable: CAR $_{\mathrm{i}, t+5, t+14}$ Panel A: Abnormal Short Selling and Future Abnormal Market Return

\begin{tabular}{|c|c|c|c|c|c|c|}
\hline \multirow[t]{4}{*}{ Dependent Variable } & \multicolumn{6}{|c|}{ 10-Day CAR } \\
\hline & \multicolumn{2}{|c|}{ Full Sample } & \multicolumn{2}{|c|}{ Cost Restructuring } & \multicolumn{2}{|c|}{ Asset Restructuring } \\
\hline & [1] & [2] & [3] & [4] & [5] & [6] \\
\hline & $\underline{\text { Coef }}$ & Coef & Coef & Coef & Coef & Coef \\
\hline \multirow[t]{2}{*}{$\mathrm{ABSS}_{\mathrm{i}, \mathrm{t}, \mathrm{t}+4}$} & $-0.006 *$ & $-0.006 *$ & $-0.021 * * *$ & $-0.022 * * *$ & -0.002 & -0.002 \\
\hline & {$[-1.72]$} & {$[-1.80]$} & {$[-2.67]$} & {$[-2.71]$} & {$[-0.50]$} & {$[-0.69]$} \\
\hline \multirow[t]{2}{*}{$\mathrm{CAR}_{\mathrm{i}, \mathrm{t}, \mathrm{t}+4}$} & $0.094 * *$ & $0.091 * *$ & $0.143 * *$ & $0.143 *$ & 0.056 & 0.053 \\
\hline & {$[2.58]$} & {$[2.48]$} & [1.98] & {$[1.95]$} & {$[1.33]$} & {$[1.25]$} \\
\hline \multirow[t]{2}{*}{$\mathrm{CAR}_{\mathrm{i}, \mathrm{t}-5, \mathrm{t}-1}$} & $-0.122 * *$ & $-0.128 * *$ & $-0.169 *$ & $-0.172 *$ & $-0.110 *$ & $-0.120 *$ \\
\hline & {$[-2.35]$} & {$[-2.44]$} & {$[-1.66]$} & {$[-1.67]$} & {$[-1.84]$} & {$[-1.97]$} \\
\hline \multirow[t]{2}{*}{ SRATIO $_{i, t-5, t-1}$} & 0.016 & 0.016 & 0.002 & 0.005 & 0.028 & 0.022 \\
\hline & {$[0.91]$} & {$[0.85]$} & {$[0.08]$} & {$[0.18]$} & {$[1.21]$} & {$[0.90]$} \\
\hline \multirow[t]{2}{*}{ PVOLT $_{i, t, t+4}$} & $0.648 * * *$ & $0.665 * * *$ & 0.273 & 0.200 & $0.728 * * *$ & $0.773 * * *$ \\
\hline & {$[3.18]$} & {$[3.14]$} & {$[0.70]$} & {$[0.49]$} & {$[3.00]$} & {$[3.04]$} \\
\hline \multirow[t]{2}{*}{ PVOLT $_{i, t-5, t-1}$} & $-0.441 * *$ & -0.358 & $-0.71 *$ & $-0.847 * *$ & -0.238 & -0.115 \\
\hline & {$[-2.03]$} & {$[-1.50]$} & {$[-1.92]$} & {$[-2.01]$} & {$[-0.87]$} & {$[-0.39]$} \\
\hline \multirow[t]{2}{*}{$\mathrm{ABVOL}_{\mathrm{i}, \mathrm{t}, \mathrm{t}+4}$} & 0.006 & 0.006 & $0.025 * * *$ & $0.026 * * *$ & 0.000 & 0.001 \\
\hline & {$[1.40]$} & [1.49] & {$[2.67]$} & {$[2.74]$} & {$[-0.03]$} & {$[0.19]$} \\
\hline \multirow[t]{2}{*}{ PRIORLOSS } & -0.008 & -0.008 & & 0.003 & & -0.013 \\
\hline & {$[-1.21]$} & {$[-0.94]$} & & {$[0.21]$} & & {$[-1.08]$} \\
\hline \multirow[t]{2}{*}{ PRIORBM } & & 0.008 & & -0.013 & & 0.008 \\
\hline & & {$[0.86]$} & & {$[-0.64]$} & & {$[0.68]$} \\
\hline \multirow[t]{2}{*}{ PRIORSIZE } & & 0.001 & & -0.003 & & 0.002 \\
\hline & & {$[0.28]$} & & {$[-0.56]$} & & {$[0.59]$} \\
\hline \multirow[t]{2}{*}{ Intercept } & -0.008 & -0.019 & 0.02 & 0.051 & $-0.018 * *$ & -0.037 \\
\hline & {$[-1.21]$} & {$[-0.80]$} & [1.44] & {$[1.05]$} & {$[-2.54]$} & {$[-1.39]$} \\
\hline Observations & 753 & 753 & 243 & 243 & 510 & 510 \\
\hline Adj. $R^{2}$ & 0.023 & 0.022 & 0.044 & 0.035 & 0.030 & 0.029 \\
\hline
\end{tabular}

This table reports regression results from the equation below with t-statistics reported in brackets [ ].

$C_{A} R_{i, t+5, t+k}=\beta_{0}+\beta_{1} A B S S_{i, t, t+4}+\beta_{2} C A R_{i, t, t+4}+\beta_{3} C A R_{i, t-5, t-1}+\beta_{4}$ SRATIO $_{i, t-5, t-1}+\beta_{5}$ PVOLT $_{i, t, t+4}+\beta_{6}$ PVOLT $_{i, t-5, t-1}+\beta_{7}$ $A B V_{i, t, t+4}+\beta_{8}$ PRIORLOSS $+\beta{ }_{9}$ PRIORBM $+\beta_{10}$ PRIORSIZE $+\varepsilon$

$*, * *, * * *$ denote statistical significance at the $0.10,0.05$, and the 0.01 levels, respectively.

Variable definitions appear in Appendix I 
TABLE 6 (continued)

Regression (Hypothesis 3 and 3A): Dependent Variable: Future CAR: CAR $_{i, t+5, t+k}$ Panel B: For Full Sample and for Different Types of Restructuring Announcements

\begin{tabular}{|c|c|c|c|c|c|c|c|}
\hline \multicolumn{2}{|c|}{ Dependent Variables } & \multicolumn{2}{|c|}{$\begin{array}{c}\text { 1-Month CAR } \\
\text { CAR }_{\mathrm{i}, t+5, \mathrm{t}+34} \\
\end{array}$} & \multicolumn{2}{|c|}{$\begin{array}{c}\text { 2-Month CAR } \\
\text { CAR }_{\mathrm{i}, \mathrm{t}+5, \mathrm{t}+64}\end{array}$} & \multicolumn{2}{|c|}{$\begin{array}{c}\text { 3-Month CAR } \\
\text { CAR }_{\mathrm{i}, \mathrm{t}+5, \mathrm{t}+94}\end{array}$} \\
\hline & & Coef & $\overline{\text { t-stat }}$ & Coef & t-stat & Coef & t-stat \\
\hline \multirow[t]{4}{*}{ Full Sample } & $\mathrm{ABSS}_{\mathrm{i}, \mathrm{t}, \mathrm{t}+4}$ & $-0.010 *$ & -1.76 & $-0.015 *$ & -2.01 & -0.014 & -1.52 \\
\hline & Controls & 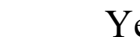 & & $\mathrm{Y}$ & & $\mathrm{Y}$ & \\
\hline & $\mathrm{N}$ & 75 & & 75 & & 75 & \\
\hline & Adj. $R^{2}$ & 0.0 & & 0.0 & & 0.0 & \\
\hline \multirow{3}{*}{\multicolumn{2}{|c|}{ Dependent Variables }} & \multirow{2}{*}{\multicolumn{2}{|c|}{$\begin{array}{c}\text { 1-Month CAR } \\
\text { CAR }_{\mathrm{i}, \mathrm{t}+5, \mathrm{t}+34}\end{array}$}} & \multirow{2}{*}{\multicolumn{2}{|c|}{$\begin{array}{c}\text { 2-Month CAR } \\
\text { CAR }_{\mathrm{i}, t+5, \mathrm{t}+64}\end{array}$}} & \multirow{2}{*}{\multicolumn{2}{|c|}{$\begin{array}{c}\text { 3-Month CAR } \\
\text { CAR }_{\mathrm{i}, \mathrm{t}+5,++94}\end{array}$}} \\
\hline & & & & & & & \\
\hline & & Coef & t-stat & Coef & t-stat & Coef & t-stat \\
\hline Cost & $\mathrm{ABSS}_{\mathrm{i}, \mathrm{t}, \mathrm{t}+4}$ & $-0.035 *$ & -2.48 & -0.038 * & -2.05 & $-0.049 *$ & -2.14 \\
\hline \multirow{3}{*}{ Restructuring } & Controls & \multicolumn{2}{|c|}{ Yes } & \multicolumn{2}{|c|}{ Yes } & \multicolumn{2}{|c|}{ Yes } \\
\hline & $\mathrm{N}$ & \multicolumn{2}{|c|}{243} & \multicolumn{2}{|c|}{243} & \multicolumn{2}{|c|}{243} \\
\hline & Adj. $R^{2}$ & \multicolumn{2}{|c|}{0.097} & \multicolumn{2}{|c|}{0.063} & \multicolumn{2}{|c|}{0.0431} \\
\hline \multirow{3}{*}{\multicolumn{2}{|c|}{ Dependent Variables }} & \multirow{2}{*}{\multicolumn{2}{|c|}{$\begin{array}{c}\text { 1-Month CAR } \\
\text { CAR }_{\mathrm{i}, \mathrm{t}+5, \mathrm{t}+34}\end{array}$}} & \multirow{2}{*}{\multicolumn{2}{|c|}{$\begin{array}{c}\text { 2-Month CAR } \\
\text { CAR }_{\mathrm{i}, \mathrm{t}+5, \mathrm{t}+64} \\
\end{array}$}} & \multirow{2}{*}{\multicolumn{2}{|c|}{$\begin{array}{c}\text { 3-Month CAR } \\
\text { CAR }_{\mathrm{i}, \mathrm{t}+5, \mathrm{t}+94}\end{array}$}} \\
\hline & & & & & & & \\
\hline & & Coef & t-stat & Coef & t-stat & Coef & t-stat \\
\hline Asset & $\mathrm{ABSS}_{\mathrm{i}, \mathrm{t}, \mathrm{t}+4}$ & -0.001 & -0.24 & -0.008 & -0.92 & -0.005 & -0.52 \\
\hline \multirow{3}{*}{ Restructuring } & Controls & \multicolumn{2}{|c|}{ Yes } & \multicolumn{2}{|c|}{ Yes } & \multicolumn{2}{|c|}{ Yes } \\
\hline & $\mathrm{N}$ & \multicolumn{2}{|c|}{510} & \multicolumn{2}{|c|}{510} & \multicolumn{2}{|c|}{510} \\
\hline & Adj. $R^{2}$ & \multicolumn{2}{|c|}{0.030} & \multicolumn{2}{|c|}{0.0352} & \multicolumn{2}{|c|}{0.0154} \\
\hline
\end{tabular}

This table reports regression results from the equation below.

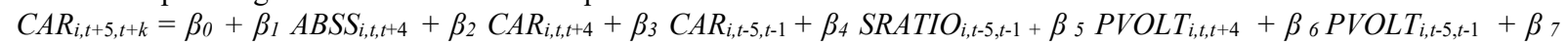
$A B V O L_{i, t, t+4}+\beta_{8}$ PRIORLOSS $+\beta{ }_{9}$ PRIORBM $+\beta_{10}$ PRIORSIZE $+\varepsilon$.

$*, * *, * * *$ denote statistical significance at the $0.10,0.05$, and the 0.01 levels, respectively.

Variable definitions appear in Appendix I. 
TABLE 6 (continued)

Regression (Hypothesis 3B): Dependent Variable: Future CAR: CAR $\mathbf{R}_{\mathrm{i}, \mathrm{t}+\mathbf{5}, \mathrm{t}+\mathrm{k}}$ Panel C: For Other Exit Activities Sample

\begin{tabular}{|c|c|c|c|c|c|c|c|c|c|}
\hline \multirow[t]{2}{*}{ Dependent Variables } & & \multicolumn{2}{|c|}{$\begin{array}{l}\text { 10-Day CAR } \\
\text { CAR }_{\mathrm{i}, \mathrm{t}+5, \mathrm{t}+14}\end{array}$} & \multicolumn{2}{|c|}{$\begin{array}{c}\text { 1-Month CAR } \\
\text { CAR }_{\mathrm{i}, t+5, t+34}\end{array}$} & \multicolumn{2}{|c|}{$\begin{array}{c}\text { 2-Month CAR } \\
\text { CAR }_{\mathrm{i}, \mathrm{t}+5, \mathrm{t}+64}\end{array}$} & \multicolumn{2}{|c|}{$\begin{array}{c}\text { 3-Month CAR } \\
\text { CAR }_{\mathrm{i}, \mathrm{t}+5, \mathrm{t}+94}\end{array}$} \\
\hline & & Coef & t-stat & Coef & t-stat & Coef & t-stat & Coef & t-stat \\
\hline \multirow[t]{4}{*}{ Other Exit Activities } & $\mathrm{ABSS}_{\mathrm{i}, \mathrm{t}, \mathrm{t}+4}$ & 0.006 & 0.46 & -0.006 & -0.44 & -0.014 & -0.73 & 0.012 & 0.44 \\
\hline & Controls & \multicolumn{2}{|c|}{ Yes } & \multicolumn{2}{|c|}{ Yes } & \multicolumn{2}{|c|}{ Yes } & \multicolumn{2}{|c|}{ Yes } \\
\hline & $\mathrm{N}$ & \multicolumn{2}{|c|}{269} & \multicolumn{2}{|c|}{269} & \multicolumn{2}{|c|}{269} & \multicolumn{2}{|c|}{269} \\
\hline & Adj. $R^{2}$ & \multicolumn{2}{|c|}{0.099} & \multicolumn{2}{|c|}{0.016} & \multicolumn{2}{|c|}{0.031} & \multicolumn{2}{|c|}{0.005} \\
\hline
\end{tabular}

This table is based on the equation below.

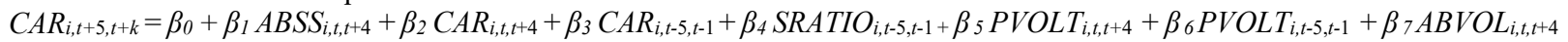
$+\beta_{8}$ PRIORLOSS $+\beta_{9}$ PRIORBM $+\beta_{10}$ PRIORSIZE $+\varepsilon$.

The sample of 300 exit activities (Table 1) is reduced (269) for missing information for control variables (PRIORLOSS, PRIORBM, and PRIORSIZE).

Standard errors are clustered by firm and day.

\# indicates the variable used in the regression is averaged over five days.

$*, * *, * * *$ denote statistical significance at the $0.10,0.05$, and the 0.01 levels, respectively.

Variable definitions appear in Appendix I. 
TABLE 7

Regression (Additional test): Restructuring sample (treatment sample) compared to non-restructuring sample (control sample)

\begin{tabular}{|c|c|c|}
\hline \multirow[t]{3}{*}{ Dependent Variable } & \multicolumn{2}{|c|}{ SRATIOi,t,t+4 } \\
\hline & {$[1]$} & \\
\hline & Coefficient & t-stat \\
\hline \multirow[t]{2}{*}{ RESTRDUMMY $_{i, t}$} & $0.035 * * *$ & 4.69 \\
\hline & {$[0.007]$} & \\
\hline CONTROLS & YES & \\
\hline Industry Fixed Effects & YES & \\
\hline Year Fixed Effects & YES & \\
\hline Observations & 1011 & \\
\hline Adj. $R^{2}$ & 0.716 & \\
\hline Treatment Sample & 515 & \\
\hline Control Sample & 496 & \\
\hline
\end{tabular}

This table reports regression results from the equation below with t-statistics reported in brackets [ ].

$S_{R A T I O}^{i, t, t+4}=\beta_{0}+\beta_{1}$ RESTDUMMY $_{i, t}+\beta_{2}$ RET $_{i, t, t+4}+\beta_{3}$ RET $_{i, t-5, t-1}+\beta_{4}$ SRATIO $_{i, t-5, t-1}+\beta_{5}$ PVOLT $_{i, t, t+4}+\beta_{6}$ PVOLT $_{i, t-5, t-1}+$ $\beta_{7}$ TURNOVER $_{i, t-5, t-1}+\varepsilon$.

$\operatorname{RESTDUMMY} Y_{i, t}$ equals 1 if the firm announces a restructuring action (treatment) and 0 otherwise.

The sample consists of 1011 observations (reported in table 9), where the number of restructuring firms is 515 and the number of matched control firms is 496.

$*, * *, * * *$ denotes statistical significance at the $0.10,0.05$, and the 0.01 levels, respectively.

Definitions of other independent variables are reported in Appendix I. 
TABLE 8

Pre-Announcement Short Interest (Hypothesis H1): Dependent Variable: SRATIO $_{i, t-5, t-1}$

\begin{tabular}{|c|c|c|c|}
\hline Dependent Variable & SRATIO $_{\mathrm{i}, \mathrm{t}-5, \mathrm{t}-1}$ & SRATIO $_{\mathrm{i}, \mathrm{t}-5, \mathrm{t}-1}$ & SRATIO $_{\mathrm{i}, \mathrm{t}-5, \mathrm{t}-1}$ \\
\hline \multirow{4}{*}{ DUMMYREST $_{\mathrm{i}, \mathrm{t}}$} & Full Sample & Cost Restructuring & Asset Restructuring \\
\hline & [1] & {$[2]$} & [3] \\
\hline & -0.003 & -0.007 & -0.001 \\
\hline & {$[-1.31]$} & {$[-1.45]$} & {$[-0.39]$} \\
\hline Controls & YES & YES & YES \\
\hline Adj. $R^{2}$ & 0.926 & 0.936 & 0.922 \\
\hline Stock FE & YES & YES & YES \\
\hline Day FE & YES & YES & YES \\
\hline $\mathrm{N}$ (event days) & 854 & 289 & 565 \\
\hline $\mathrm{N}$ (non event days) & 54,835 & 18,362 & 36,473 \\
\hline $\mathrm{N}=$ Total & 55,689 & 18,651 & 37,038 \\
\hline
\end{tabular}

This table reports regression results from the equation below with t-statistics reported in brackets [ ].

SRATIO $_{i, t-5, t-1}=\beta_{0}+\beta_{1}$ DUMMYREST $_{i, t}+\beta_{2}$ RET $_{i, t-5, t-1}+\beta_{3}$ PVOLT $_{i, t-5, t-1}+\beta_{4}$ TURNOVER $_{i, t-5, t-1}+\varepsilon$.

Standard errors are clustered by firm and day.

$*, * *, * * *$ denotes statistical significance at the $0.10,0.05$, and the 0.01 levels, respectively.

Definitions of other independent variables are reported in Appendix I. 
TABLE 9

State Fixed Effect and Local WARN Act

Dependent Variable: SRATIO $_{i, t, t+4}$

\begin{tabular}{|c|c|c|c|c|}
\hline & Full Sample & $\begin{array}{c}\text { Cost } \\
\text { Restructuring }\end{array}$ & $\begin{array}{c}\text { Asset } \\
\text { Restructuring }\end{array}$ & Local_Warn_Act \\
\hline & & & & Local_Warn $=1$ Local_Warn $=0$ \\
\hline \multirow{3}{*}{ DUMMYREST $_{t}$} & $\llbracket 1]$ & $\lfloor 2\rfloor$ & $\lfloor 3\rfloor$ & [4] \\
\hline & $0.028 * * *$ & $0.030 * * *$ & $0.026 * * *$ & $0.025 * * *$ \\
\hline & {$[6.61]$} & {$[3.57]$} & {$[4.99]$} & {$[3.85]$} \\
\hline Adj. $R^{2}$ & 0.779 & 0.793 & 0.774 & 0.769 \\
\hline Stock FE & YES & YES & YES & YES \\
\hline Day FE & YES & YES & YES & YES \\
\hline State FE & YES & YES & YES & YES \\
\hline $\mathrm{N}$ (event days) & 839 & 283 & 556 & 309 \\
\hline $\mathrm{N}$ (non event days) & 53,868 & 17,988 & 35,880 & 19,597 \\
\hline $\mathrm{N}=$ Total & 54,707 & 18,271 & 36,436 & 19,906 \\
\hline
\end{tabular}

This table reports regression results from the equation below with t-statistics reported in brackets [ ].

$S_{R A T I O}^{i, t, t+4}=\beta_{0}+\beta_{1}$ DUMMYREST $_{i, t}+\beta_{2}$ RET $_{i, t, t+4}+\beta_{3}$ RET $_{i, t-5, t-1}+\beta_{4}$ SRATIO $_{i, t-5, t-1}+\beta_{5}$ PVOLT $_{i, t, t+4}+\beta_{6}$ PVOLT Ti,t-5,t-1 $+\beta_{7}$ TURNOVER $_{i, t-5, t-1}+\varepsilon$.

Of total sample of 839 restructuring announcements, 530 announcements of restructuring actions are related to the states, which have passed local WARN act (column 4 ) and 309 announcements are in other states (column 5). Local WARN act requires advance notice and severance payments to employees for mass layoff or plant closing.

We follow Chunyu and Tran (2018), to get the list of states, which have passed local WARN act. States passing local WARN act are CA, CT, HI, IL, IA, ME, MD, MA, MI, MN, NH, NJ, NY, TN, VT, and WI.

Columns 1 through 3 represent the fixed effect estimates by stock, days, and states.

$*, * *, * * *$ denotes statistical significance at the $0.10,0.05$, and the 0.01 levels, respectively. 